\title{
Fuel reactor model validation: assessment of the key parameters affecting the chemical-looping combustion of coal
}

Alberto Abad, ${ }^{a}$ Juan Adánez, ${ }^{a}$ Luis F. de Diego, ${ }^{a}$ Pilar Gayán, ${ }^{a}$ Francisco García-Labiano, ${ }^{a}$ Anders Lyngfelt ${ }^{b}$

${ }^{a}$ Department of Energy and Environment, Instituto de Carboquímica (ICB-CSIC), Miguel Luesma Castán 4, E-50018, Zaragoza, Spain.

${ }^{\mathrm{b}}$ Department of Energy and Environment, Chalmers University of Technology, S-41296, Göteborg, Sweden.

* Corresponding author: Fax: +34 976 733318; Tel: +34 976 733977; E-mail: abad@icb.csic.es (A. Abad)

\begin{abstract}
The success of a Chemical Looping Combustion (CLC) system for coal combustion is greatly affected by the performance of the fuel reactor. When coal is gasified in-situ in the fuel reactor, several parameters affect the coal conversion, and hence the capture and combustion efficiencies. In this paper, a mathematical model for the fuel reactor is validated against experimental results obtained in a $100 \mathrm{~kW}_{\text {th }}$ CLC unit when reactor temperature, solids circulation flow rate or solids inventory are varied. This is the first time that a mathematical model for Chemical Looping Combustion of coal with in-situ gasification ( $i \mathrm{G}-\mathrm{CLC}$ ) has been validated against experimental results obtained in a continuously operated unit. The validated model can be used to evaluate the relevance of operating conditions on process efficiency. Model simulations showed that the reactor temperature, the solids circulation flow rate and the solids inventory were the most
\end{abstract}


relevant operating conditions affecting the oxygen demand. However, high values of the solids circulation flow rate must be prevented because they cause a decrease in the $\mathrm{CO}_{2}$ capture. The high values of $\mathrm{CO}_{2}$ capture efficiency obtained were due to the highly efficient carbon stripper. The validated model is a helpful tool in designing the fuel reactor to optimize the CLC process. $\mathrm{A} \mathrm{CO}_{2}$ capture efficiency of $\eta_{\mathrm{CC}}=98.5 \%$ and a total oxygen demand of $\Omega_{\mathrm{T}}=9.6 \%$ is predicted, operating at $1000^{\circ} \mathrm{C}$ and $1500 \mathrm{~kg} / \mathrm{MW}_{\text {th }}$ in the fuel reactor.

\section{Introduction}

In recent years, increasing attention has been paid to the application of Chemical-Looping Combustion (CLC) for coal combustion with $\mathrm{CO}_{2}$ capture (Adanez et al., 2012). The CLC process is based on the transfer of oxygen from air to the fuel by means of a solid oxygen carrier which avoids direct contact between fuel and air. The oxygen carrier is composed of a metal oxide, $\mathrm{Me}_{\mathrm{x}} \mathrm{O}_{\mathrm{y}}$, and often uses an inert material acting as support. The $\mathrm{CO}_{2}$ capture is inherent in this process. Fig. 1 shows a general scheme of the CLC system using coal as fuel.

A CLC system consists mainly of two reactors, namely air and fuel reactors, with the oxygen carrier circulating between the two. In the in-situ Gasification Chemical Looping Combustion concept ( $i \mathrm{G}-\mathrm{CLC})$, coal is fed to the fuel reactor, where the $i n$-situ gasification of coal takes place, generating volatile matter and gasification products through reactions (1-3). Reducing gases evolving during gasification are oxidized by reactions (4-6) with the oxygen carrier, $\mathrm{Me}_{\mathrm{x}} \mathrm{O}_{\mathrm{y}}$, The water-gas shift (WGS) reaction (7) can also be significant to the process as $\mathrm{CO}, \mathrm{H}_{2}$, $\mathrm{CO}_{2}$ and $\mathrm{H}_{2} \mathrm{O}$ are present in gases. The reduced oxygen carrier, $\mathrm{Me}_{\mathrm{x}} \mathrm{O}_{\mathrm{y}-1}$, is transferred to the air reactor where it is regenerated with air-reaction (8)- to be later transferred to the fuel reactor and start a new cycle. In $i \mathrm{G}-\mathrm{CLC}$, the $\mathrm{CO}_{2}$ capture efficiency can be reduced if char particles are bypassed to the air reactor where they will be burnt (9), releasing some $\mathrm{CO}_{2}$ with the depleted air. 


$$
\begin{aligned}
& \text { Coal }(\mathrm{s}) \rightarrow \mathrm{H}_{2} \mathrm{O}(\mathrm{g})+\text { Volatile matter }(\mathrm{g})+\text { Char }(\mathrm{s}) \\
& \mathrm{Char}(\mathrm{s})+\mathrm{H}_{2} \mathrm{O}(\mathrm{g}) \rightarrow \mathrm{H}_{2}(\mathrm{~g})+\mathrm{CO}(\mathrm{g})+\text { ash }(\mathrm{s}) \\
& \mathrm{Char}(\mathrm{s})+\mathrm{CO}_{2}(\mathrm{~g}) \rightarrow 2 \mathrm{CO}(\mathrm{g})+\text { ash }(\mathrm{s}) \\
& \mathrm{CH}_{4}+4 \mathrm{Me}_{\mathrm{x}} \mathrm{O}_{\mathrm{y}} \rightarrow \mathrm{CO}_{2}+2 \mathrm{H}_{2} \mathrm{O}+4 \mathrm{Me}_{\mathrm{x}} \mathrm{O}_{\mathrm{y}-1} \\
& \mathrm{CO}+\mathrm{Me}_{\mathrm{x}} \mathrm{O}_{\mathrm{y}} \rightarrow \mathrm{CO}_{2}+\mathrm{Me}_{\mathrm{x}} \mathrm{O}_{\mathrm{y}-1} \\
& \mathrm{H}_{2}+\mathrm{Me}_{\mathrm{x}} \mathrm{O}_{\mathrm{y}} \rightarrow \mathrm{H}_{2} \mathrm{O}+\mathrm{Me}_{\mathrm{x}} \mathrm{O}_{\mathrm{y}-1} \\
& \mathrm{H}_{2} \mathrm{O}+\mathrm{CO} \leftrightarrow \mathrm{H}_{2}+\mathrm{CO}_{2} \\
& \mathrm{Me}_{\mathrm{x}} \mathrm{O}_{\mathrm{y}-1}+1 / 2 \mathrm{O}_{2} \rightarrow \mathrm{Me}_{\mathrm{x}} \mathrm{O}_{\mathrm{y}} \\
& \text { Char }(\mathrm{s})+1 / 2 \mathrm{O}_{2} \rightarrow \mathrm{CO}_{2}+\operatorname{ash}(\mathrm{s})
\end{aligned}
$$

A fundamental part of the reliability of a CLC system with coal is based on the behaviour of the fuel reactor. This will determine the loss of unburnt gas in the exit gas stream and the amount of char exiting from the fuel reactor. The separation of char from oxygen carrier particles in a carbon stripper and their recirculation to the fuel reactor has been proposed in order to reduce the carbon flow entering the air reactor (Cao and Pan, 2006).

Great advances have been made in the evaluation of operational conditions -e.g. reactor temperature (Berguerand and Lyngfelt, 2009; Cuadrat et al., 2011; Cuadrat et al., 2011a and 2011b; Gu et al., 2011; Song et al., 2013), solids circulation flow rate (Cuadrat et al., 2012a), fluidizing gas flow or composition (Cuadrat et al., 2012a), coal feeding rate or coal rank (Cuadrat et al., 2012b)- or the effect of oxygen carrier properties (Mediara et al., 2013; Linderholm et al., 2012) on the CLC performance from experimental work in CLC units with coal. In all these cases, gasification of coal is an intermediate step taking place in the fuel reactor. In these studies, high $\mathrm{CO}_{2}$ capture can be achieved by using high temperatures and/or implementing a carbon separation system between the fuel and air reactors. However, complete combustion of gases from the fuel reactor has not been achieved in existing iG-CLC units 
(Gayán et al., 2013).

Modelling and simulation of the $i \mathrm{G}-\mathrm{CLC}$ system is an important tool for analysing the effect of various operational conditions. Thus, the main issues affecting the process have been identified. Some papers have been presented in the literature for modelling the process involved in the fuel reactor of an $i \mathrm{G}$-CLC system with different degrees of complexity in their formulation (Cuadrat et al., 2012c; Kramp et al., 2012; Strölhe et al., 2010; Brown et al., 2010; Schöny et al., 2011; Mahalatkar et al., 2011; Abad et al., 2013; García-Labiano et al., 2013; Berguerand et al., 2011; Markström et al., 2013a). Any mathematical model should be validated against experimental results in order to be confident in its predictions. Simulation and validation of theoretical predictions are found for batch fluidized bed reactors (Brown et al., 2010; Mahalatkar et al., 2011). Results from analytical models have also been compared to results from continuously operated units in the range 0.5-100 kW (Cuadrat et al., 2012c; Berguerand et al., 2011; Markström et al., 2013a), but so far no comprehensive numerical model that has been validated against experimental results obtained from a continuously operated CLC unit with coal has been found in the literature. This validation step is required before the design, optimization, and scaleup of the process where a mathematical tool is used.

In this paper, a previously formulated (Abad et al., 2013; García-Labiano et al., 2013) mathematical model was validated against experimental results obtained in a $100 \mathrm{~kW}_{\text {th }}$ CLC unit erected at Chalmers University of Technology. Later, this model was used to determine the more relevant parameters influencing the performance of the CLC process. The information shown in this paper was then used to identify the operating conditions and design parameters which optimize the $\mathrm{CO}_{2}$ capture and combustion efficiency of the process. 


\section{Fuel reactor model}

\subsection{General description of the theoretical model}

In a previous paper (Abad et al., 2013), a theoretical model describing the fuel reactor in the insitu Gasification Chemical-Looping Combustion process (iG-CLC) was presented. The model developed included the reactor fluid dynamics, coal conversion and reaction of the oxygen carrier with gases evolved from coal. More information on the model was presented in Abad et al. (2013) and García-Labiano et al. (2013)

The model developed was focused on the fuel reactor of the $1 \mathrm{MW}_{\text {th }}$ CLC unit built at TU Darmstadt. Details about the $1 \mathrm{MW}_{\text {th }}$ CLC unit can be found elsewhere (Orth et al., 2012). The fuel reactor was a fluidized bed working at a high-velocity regime. The fluid dynamic model considers the gas and solids flows inside the reactor and the gas-solids mixing patterns in the different regions in which it could be divided. The reactor was divided into two vertical regions with respect to axial concentration and backmixing of solids, see Fig. 2: 1) a dense region in the bottom bed with a high, roughly constant concentration of solids; and 2) a freeboard above the dense region, the dilute region, where there is a pronounced decrease in the concentration of solids as height increases.

The model can be considered 1.5 dimensional, with the main dimension in the axial direction. Gas distribution and mixing between the emulsion and bubbles in the dense region was taken into account. Thus, the gas flow in the dense region was shared between the emulsion and bubble phases, with gas mixing between the two, controlled by diffusion. Solids were in the emulsion phase, where the gas flow maintained the minimum fluidizing conditions; the remaining gas passed through bubbles, with no solids present. The dilute region had a cluster phase and a transport or dispersed phase. Both the cluster and transport phases were superimposed but with 
different mixing behaviour. The cluster phase had a strong solids backmix with solids in the dense region. The transport phase was characterized by a core/annulus flow structure. A net flow upward of solids passed through the core and particle backmixing occurred at the reactor walls. Also, a lateral exchange of solids in the dilute region between the core and an annulus, close to the reactor wall, was included.

Mass balances for the different reacting compounds and products were developed for each phase in the dense region and the dilute region. The general pathway for coal conversion was shown in Eqs. (1-6), and started with drying, pyrolysis and gasification to produce gaseous compounds. The drying and pyrolysis processes were assumed to occur instantaneously at the feeding point of the coal. Next, the gaseous compounds reacted with the oxygen carrier particles towards $\mathrm{CO}_{2}$ and $\mathrm{H}_{2} \mathrm{O}$. Char gasification and oxygen carrier reduction kinetics were included in the model. However, the direct coal conversion by solid-solid reaction with oxygen carrier particles was not included, as it was demonstrated to be of lower relevance in a fluidized bed environment (Mendiara et al., 2013a).

The presence of a carbon separation system was also evaluated. The processes in the carbon separation system were not modelled, but the effect of char separation and recirculation to the fuel reactor on the performance of the fuel reactor could be analysed.

The main outputs of the model were (1) the fluid dynamics structure of the reactor, e.g. height of the dense region and profiles of concentration and flow of solids in the dilute region; (2) the axial profiles of gas composition and flows $\left(\mathrm{CO}, \mathrm{H}_{2}, \mathrm{CH}_{4}, \mathrm{CO}_{2}\right.$ and $\left.\mathrm{H}_{2} \mathrm{O}\right)$; (3) the axial profile of char concentration in the reactor; (4) the axial profiles of average conversions for the oxygen carrier and char; (5) the gas composition and solids flow in the upper reactor exit to cyclone; and (6) the char flow to the air reactor.

From these outputs, the performance of the $i \mathrm{G}$-CLC system was assessed by calculating the $\mathrm{CO}_{2}$ 
capture efficiency, the char conversion, the combustion efficiency in the fuel reactor and the oxygen demand of the $i \mathrm{G}$-CLC process, called the performance parameters here.

The effect of several operational parameters, including temperature, solids inventory or the oxygen carrier to fuel ratio, on the performance parameters were previously analysed for the 1 MW $_{\text {th }}$ CLC unit at TU Darmstadt (Abad et al., 2013; García-Labiano et al., 2013). In this paper, the model is adapted to the conditions (geometry and flows) in the $100 \mathrm{~kW}_{\text {th }}$ CLC unit built at Chalmers UT (Markström et al., 2013b). Experimental results obtained in this facility were used to validate the mathematical model.

\subsection{Model adaptation to the $100 \mathrm{~kW}_{\text {th }}$ CLC unit at Chalmers University of Technology}

Fig. 3 shows the schematic diagram of the $100 \mathrm{~kW}_{\text {th }}$ CLC unit erected at Chalmers University of Technology. The system basically consists of a fuel reactor (FR), an air reactor (AR), a carbon stripper (CS) and a circulation riser (CR). The conversion of the fuel occurs mainly in the fuel reactor, which is a high-velocity fluidized-bed. Solid particles can be entrained to the cyclone CY2 or enter into the circulation riser through loop seal LS3. Particles separated in cyclone CY2 are returned to the fuel reactor by loop seal LS2, where the solid fuel is fed. The circulation riser is used to elevate particles. Particles entrained from the circulation riser are separated in cyclone CY3 and sent to the carbon stripper, whereas gas coming from CR goes to entry A in the fuel reactor. In the carbon stripper, char particles are separated from the oxygen carrier particles. Gas and char from the carbon stripper go to the fuel reactor through entry B. Oxygen carrier particles are led to the air reactor through loop seal LS4. Entrained particles from the air reactor are separated in cyclone CY1 and introduced into the fuel reactor through loop seal LS1 and later by entry C. Circulation is controlled by the fluidizing velocity of both air reactor and circulation riser. These flows also control the solids inventory in the fuel reactor. More information on the 
$100 \mathrm{~kW}_{\text {th }}$ CLC unit can be found elsewhere (Markström et al., 2013b).

The main dimensions of the reactor are shown in Table 1. In addition to the difference in geometry between the $1 \mathrm{MW}_{\text {th }}$ and $100 \mathrm{~kW}_{\text {th }}$ units, all inlet gas and solids streams from LS1, LS2, LS3, LS4, CR and CS are included in the mathematical model, following the design of the $100 \mathrm{~kW}_{\text {th }}$ CLC unit. Also, the inlet solids to the carbon stripper come from the cyclone in the 1 $\mathrm{MW}_{\text {th }}$ unit. However, solids come from the bottom bed of the fuel reactor in the $100 \mathrm{~kW}_{\text {th }}$ unit. This difference in the design concept was also taken into account in the model. Therefore, the following modifications, marked as numbers 1 to 5 in Fig. 3, have been carried out:

1. The fuel is introduced in the upper part of the loop seal LS2, where a steam flow is added. It is assumed that fuel pyrolysis is instantaneous in the feeding point. Volatiles and gas fed in LS2 enter the fuel reactor in the bottom part. Both nitrogen flows to LS2 and to the screw feeder for coal are included in gas entering from LS2 to FR. Moreover, char particles also enter the FR at point 1 . An instantaneous mixing of char particles is assumed in the dense region. Thus, the char concentration in the dense region is constant.

2. Solid particles pass through point 2 from the FR to the circulation riser (CR) through LS3. It is assumed that half of the fluidization gas flow to LS3 goes to the FR through point 2. Also, a mixture of oxygen carrier and char particles exit the FR at point 2. It is assumed that the concentration of char in this stream of solids is equal to the char concentration in the dense region of the FR. This condition is different from that of the $1 \mathrm{MW}_{\mathrm{th}} \mathrm{CLC}$ unit, where the stream of solids leaving the FR was located in the upper part of the reactor, i.e. the solids outlet towards the cyclone system. Regarding the carbon balance, the flow of carbon going from the FR to CS, $F_{C, F R}$ in mol/s, given by Eq. (58) in Abad et al. (2013) has been modified to: $F_{C, F R}=\frac{C_{C, 0} \dot{m}_{O C}}{\left(1-C_{C, 0}\right) M_{C}}$ 
with $C_{C, 0}$ being the carbon fraction in the solids present in the dense region, $\dot{m}_{O C}$ the oxygen carrier recirculation flow $(\mathrm{kg} / \mathrm{s})$, and $M_{C}$ the atomic mass of carbon $(\mathrm{kg} / \mathrm{mol})$.

3. At point 3, solids come from the air reactor, together with the gas flow from LS1.

4. At position 4, char particles separated in the CS enter the FR. The gas flow coming from CS and a fraction of the gas flow in LS4 is assumed to mix with the gases in the FR.

5. Similarly the gas flow from the CR, as well as a fraction of gas in LS3, enters the FR in position 5 .

Ilmenite was used as oxygen carrier. Due to the fairly fast activation of ilmenite particles (Cuadrat et al., 2011b; Adánez et al., 2010), the kinetic parameters for the reduction of activated ilmenite with $\mathrm{CH}_{4}, \mathrm{H}_{2}$ and $\mathrm{CO}$ were used in the model (Abad et al., 2011).

A bituminous coal from the Cerrejón coal mine in Colombia was used. Table 2 shows the composition as it was used in the $100 \mathrm{~kW}_{\text {th }}$ unit. The lower heating value is $24.64 \mathrm{MJ} / \mathrm{kg}$ and the mean average particle diameter is $47 \mu \mathrm{m}$. The product distribution during pyrolysis was calculated following the model described by Matthesius et al. (1987) $\mathrm{CO}, \mathrm{H}_{2}$ and $\mathrm{CH}_{4}$ were assumed to be the only reducing gases in the mass balances, as it was shown that these were the main compounds after devolatilization in an $i \mathrm{G}-\mathrm{CLC}$ system (Cuadrat et al., 2011b). The product distribution after devolatilization is shown in Table 3. The kinetics for char gasification have been presented in a previous paper (Cuadrat et al., 2012c).

The theoretical model focuses on the processes occurring in the fuel reactor. Table 1 shows the main dimensions of the unit used in the model and the gaseous flows entering the fuel reactor, and Table 4 the experimental conditions regarding the fuel reactor. Geometrical parameters of the fuel reactor and operational conditions were taken from experiments during the seventh and eighth periods carried out under the ECLAIR project (Markström et al., 2013b). During these 
tests, steady state was reached during the working time.

Experimental conditions were methodically varied during these tests. In experiments VII-1 to VII-4, the air flow was increased; this resulted in an increase in both the oxygen carrier circulation flow and the amount of solids in the fuel reactor, as measured by the pressure drop. In experiment VII-5, the steam flow to the FR was decreased by a third, but this had no major effects. In experiment VII-6, the air reactor temperature was increased from 1000 to $1025^{\circ} \mathrm{C}$; this led to the fuel reactor temperature also increasing in comparison with experiment VII-5. In experiment VII-7, the gas flow to the CR was increased. Several effects on the fuel reactor followed, namely the solids circulation flow and temperature increased, but the solids inventory in the fuel reactor decreased. In experiment VII-8, similar conditions to VII-6 were achieved. In experiment VII-9, the steam flow to the fuel reactor was increased to the value in experiment VII-4, but a different temperature, pressure drop and solids circulation rate were reached. In experiment VIII-1, a lower solids circulation flow was used compared to experiments VII-6 and VII-8, without major variations in other parameters. Finally, experimental conditions in test VIII2 were similar to that for test VII-5, although a small variation in the fuel reactor temperature and solids inventory was observed because the air reactor temperature was different. The performance of the fuel reactor was evaluated by analysing three parameters: the solid fuel conversion $\left(\eta_{\mathrm{SF}}\right)$, the oxygen demand $\left(\Omega_{\mathrm{OD}}\right)$, and the oxide oxygen fraction $\left(\eta_{\mathrm{OO}}\right)$, which is related to the efficiency of $\mathrm{CO}_{2}$ capture (Markström et al., 2013b). Table 5 shows the values for the parameters obtained during the experimental work at Chalmers University of Technology. The solid fuel conversion is the ratio between the total flow of gaseous carbon leaving the CLC unit (through both the fuel and air reactors) and the total flow of carbon fed to the system with the coal. From results obtained with the model, the solid fuel conversion was calculated as 
$\eta_{S F}=M_{C} \frac{\left(F_{\mathrm{CO}_{2}}+F_{C O}+F_{C H_{4}}\right)_{F R}+F_{C, A R}}{f_{C} \dot{m}_{c o a l}}$

$F_{\mathrm{CO}_{2}}, F_{\mathrm{CO}}$ and $F_{\mathrm{CH}_{4}}$ being the flow of $\mathrm{CO}_{2}, \mathrm{CO}$ and $\mathrm{CH}_{4}$ exiting the fuel reactor, $F_{C, A R}$ the carbon

flow in char escaping to the air reactor, $f_{C}$ the carbon content of coal, and $\dot{m}_{\text {coal }}$ the mass-based coal feeding rate.

The carbon escaping from CY2 must be taken into account in the carbon balance to the fuel reactor-carbon stripper system. Thus, the set of Eqs. (56-60) in Abad et al. (2013) was replaced by:

$$
\begin{aligned}
F_{C, A R}= & \frac{\eta_{S F} f_{C} \dot{m}_{\text {coal }}}{M_{C}}-\int_{0}^{H_{b}}\left(1-\delta_{\mathrm{b}}\right)\left[\left(-\bar{r}_{g, H_{2} O}\right)_{\text {char }}+\left(-\bar{r}_{g, C O_{2}}\right)_{\text {char }}\right]_{e} S_{\text {react }} \mathrm{d} z- \\
& \int_{H_{b}}^{H_{r}} \xi_{g-s}\left[\left(-\bar{r}_{g, H_{2} O}\right)_{c h a r}+\left(-\bar{r}_{g, C O_{2}}\right)_{c h a r}\right]_{s p l} S_{\text {react }} \mathrm{d} z-\int_{H_{b}}^{H_{r}} \xi_{\mathrm{g}: \mathrm{s}}\left[\left(-\bar{r}_{g, H_{2} O}\right)_{\text {char }}+\left(-\bar{r}_{g, C O_{2}}\right)_{c h a r}\right]_{t r} S_{\text {react }} \mathrm{d} z
\end{aligned}
$$

Solid fuel conversion is lower than $100 \%$ because of char losses from the cyclone CY2 in the gas stream. The carbon flow not recovered by the cyclone $\mathrm{CY} 2, F_{C, e s c}$, was then calculated as

$$
F_{C, \text { esc }}=\frac{f_{C} \dot{m}_{\text {coal }}\left(1-\eta_{S F}\right)}{M_{C}}
$$

Once the carbon flow escaping from the cyclone is known, the efficiency of the cyclone can be calculated:

$$
\eta_{\text {Cyclone }}=\frac{C_{C} \dot{m}_{s}-M_{C} F_{C, \text { esc }}}{C_{C} \dot{m}_{s}}
$$

$C_{C}$ being the char fraction in solids to CY2, and $\dot{m}_{s}$ the solids flow to CY2, which are parameters calculated by the model.

The $\mathrm{CO}_{2}$ capture efficiency, $\eta_{\mathrm{CC}}$, is an important parameter in the $i \mathrm{G}$-CLC process, which is related to the fraction of carbon in coal that is exiting from the fuel reactor at the time, i.e. it is captured. From experimental results in the $100 \mathrm{~kW}_{\text {th }}$ unit, the $\mathrm{CO}_{2}$ capture efficiency is evaluated 
through the oxide oxygen fraction $\left(\eta_{\mathrm{OO}}\right)$ instead of $\eta_{\mathrm{CC}} . \eta_{\mathrm{OO}}$ is defined as the amount of oxygen used for oxidizing the particles in the air reactor, divided by the total amount of oxygen consumed in the air reactor (Markström et al., 2013b). Although the air reactor is not modelled here, $\eta_{\mathrm{Oo}}$ can be also calculated from the flow of gases exiting the fuel reactor as:

$\eta_{O O}=\frac{\left(2 F_{C O_{2}}+F_{C O}+F_{\mathrm{H}_{2} O}\right)_{F R, \text { out }}-\left(\sum F_{\mathrm{H}_{2} \mathrm{O}}\right)_{F R, \text { in }}-\frac{f_{O} \dot{m}_{\text {coal }}}{M_{O}}}{\left(2 F_{\mathrm{CO}_{2}}+F_{C O}+F_{\mathrm{H}_{2} O}\right)_{F R, \text { out }}-\left(\sum F_{\mathrm{H}_{2} O}\right)_{F R, \text { in }}-\frac{f_{O} \dot{m}_{\text {coal }}}{M_{O}}+2 F_{C, A R}}$

$\sum F_{\mathrm{H}_{2} \mathrm{O}}$ being the sum of all steam flows entering to the fuel reactor. $\eta_{\mathrm{OO}}$ is not exactly equal to the $\mathrm{CO}_{2}$ capture efficiency, $\eta_{\mathrm{CC}}$, but it is closely related. The advantage of using $\eta_{\mathrm{OO}}$ instead $\eta_{\mathrm{CC}}$ is that $\eta_{\mathrm{OO}}$ can be easily calculated from $\mathrm{O}_{2}$ and $\mathrm{CO}_{2}$ concentrations at the air reactor outlet. A key parameter affecting the $\mathrm{CO}_{2}$ capture efficiency is the efficiency of the carbon separation system, i.e. carbon stripper efficiency, $\eta_{\mathrm{CS}}$. However, the available experimental results obtained in the $100 \mathrm{~kW}_{\text {th }}$ unit are not enough to calculate the efficiency of the carbon stripper separating char particles from oxygen carrier particles. Inputs regarding the carbon flows to and from the carbon stripper are required to calculate the $\eta_{C S}$ value, but they are not available yet. The solution adopted in this work was to use the $\mathrm{CO}_{2}$ capture efficiency, $\eta_{\mathrm{CC}}$, as a target parameter; thus the experimental $\eta_{\mathrm{CC}}$ value was reproduced by the model by fitting the value of the carbon stripper efficiency. Thus, a value for the carbon stripper efficiency was determined for every experimental condition shown in Table 4, which predicts the experimental value for the $\eta_{\mathrm{OO}}$ parameter in Table 5. Once the $\eta_{C S}$ value is fixed, the rest of parameters can be calculated. The combustion efficiency of the fuel reactor was analysed by using the oxygen demand parameter. Therefore, the oxygen demand in the fuel reactor $\left(\Omega_{\mathrm{OD}}\right)$ was defined as the fraction of oxygen required to achieve complete combustion of the gases leaving the fuel reactor. It was 
calculated as:

$\Omega_{O D}=\frac{\left(0.5 y_{C O}+0.5 y_{H_{2}}+2 y_{C H_{4}}\right)_{F R, o u t}}{\Phi_{O}\left(y_{\mathrm{CO}_{2}}+y_{C O}+y_{\mathrm{CH}_{4}}\right)_{F R, \text { out }}}$

where $\Phi_{0}$ is the oxygen/carbon ratio, i.e. the ratio of moles of oxygen needed to convert the fuel completely per moles of carbon in the fuel, and $y_{i}$ is the molar fraction of species $i$ in the fuel reactor. For El Cerrejón coal $\Phi_{0}=1.179$. Thus, only the fraction of coal converted in the fuel reactor was used in the denominator to calculate the oxygen demand.

The oxygen demand in the fuel reactor is related to the combustion efficiency in the fuel reactor given in Abad et al. (2013) as

$$
\Omega_{O D}=1-\eta_{c, F R}
$$

As described by Abad et al. (2013), the model predicted that CO would be about 2-3 times more than $\mathrm{H}_{2}$ at the reactor exit. The main reason is that the water-gas shift reaction was not included and also that $\mathrm{CH}_{4}$ conversion was thought to happen in two steps: first to $\mathrm{CO}$ and $\mathrm{H}_{2} \mathrm{O}$ and later $\mathrm{CO}$ is oxidised by the oxygen carrier to $\mathrm{CO}_{2}$. Therefore, $\mathrm{CO}$ accumulated in the reactor as $\mathrm{CH}_{4}$ is being converted. However, in the experimental results, $\mathrm{CO}$ concentration values were closer to the $\mathrm{H}_{2}$ concentration. Thus, predicted $\mathrm{CO}$ concentration values are higher than experimental values (average relative error $+25 \%$ ), whereas predicted $\mathrm{H}_{2}$ values are lower than experimental values (average relative error $-30 \%$ ). However, similar theoretical and experimental values were obtained for the sum of $\mathrm{CO}$ and $\mathrm{H}_{2}$ concentrations, which suggests that some $\mathrm{CO}$ was converted to $\mathrm{H}_{2}$ via WGS reaction.

To overcome this disagreement, two modifications were made to the model:

1. The path for $\mathrm{CH}_{4}$ conversion was modified to direct oxidation to $\mathrm{CO}_{2}$ and $\mathrm{H}_{2} \mathrm{O}$, as in reaction (4). The corresponding kinetic parameters shown in Table 2 in Abad et al. (2011) for activated 
ilmenite were used.

2. Reaction kinetics for the water-gas shift (WGS) reaction were introduced, reaction (9). No relevant catalytic WGS reaction with ilmenite was previously seen (Cuadrat et al., 2012d). In addition, note the high $\mathrm{H}_{2} \mathrm{O}$ excess when compared to equilibrium conditions. With this in mind, only kinetics for the homogeneous forward WGS reaction (fWGSR) were included (Graven and Long, 1954). The fWGSR was assumed to occur in all regions in the reactor, i.e. the emulsion phase, the bubble phase and the dilute region. Thus, the corresponding term in Eqs. (44), (45) and (47) in Abad et al. (2013) for the reaction of a compound $i$ by the fWGSR was calculated as:

$$
\frac{\mathrm{d} F_{W G S, i}}{\mathrm{~d} V_{j}}=\left(1-\varepsilon_{j}\right) k_{0, f W G S} e^{-E_{f W G S} / R_{g} T} C_{C O}^{0.5} C_{H_{2} O}
$$

$\varepsilon_{\mathrm{j}}$ being porosity of the bed in the region $j$ with a volume $V_{j}$. Pre-exponential factor of kinetic constant is $k_{0, f W G S}=7.97 \cdot 10^{9}\left(\mathrm{~m}^{3} / \mathrm{mol}\right)^{0.5} \mathrm{~s}^{-1}$ and activation energy $E_{f W G S}=274.5 \mathrm{~kJ} / \mathrm{mol}$.

\section{Results: model predictions}

The developed model was used to predict the behaviour of the fuel reactor in the $100 \mathrm{~kW}_{\text {th }} \mathrm{CLC}$ plant at Chalmers University of Technology. Theoretical results were obtained for the operational conditions shown in Table 4. Furthermore, a detailed analysis is presented for test VII-5, where the gas and solids axial profiles are discussed. Fig. 4(a) shows the axial profiles for gas velocity and concentration of solids in the fuel reactor. Figs. 3(b) and 3(c) show the axial profiles for flow and concentration of gases in the fuel reactor, respectively. The separation of the dense and dilute regions can easily be observed from the profiles of concentrations of solids. The dense region is stretched out to a height of $H_{b}=0.95 \mathrm{~m}$, being characterized by roughly constant porosity. Above the dense region, the concentration of solids decreases with the reactor height. The gas velocity increases through the reactor because gases 
are generated during coal gasification. In addition, abrupt changes in gas velocity are found at the positions where the coal is fed near the distributor plate and at every point where different gaseous streams enter into the fuel reactor, i.e. from bottom to top connections to LS2, LS3, LS1, CS and CY3. Where a flow of steam enters into the reactor, an increase in the $\mathrm{H}_{2} \mathrm{O}$ content is observed, and consequently the other gases are diluted. In particular, this occurs where the flow of $\mathrm{H}_{2} \mathrm{O}$ from the carbon stripper enters the fuel reactor. The major point affecting gas velocity is the connection from the CS, due to the high steam flow used in the CS, which is higher than the steam flow fed to the FR.

Although the gas flow increased throughout the entire reactor, a decrease in the gas velocity was observed in the upper part of the reactor $(\mathrm{z}>4.1 \mathrm{~m})$. This was because the core section only increased above the height reached by the saturation value in the annulus.; see Eqs. (17-19) in Abad et al. (2013) As gas was assumed to flow through the core, the gas velocity decreased as the core section increased above $z_{\text {sat }}=4.1 \mathrm{~m}$.

The gas at the bottom of the bed is mainly composed of $\mathrm{H}_{2} \mathrm{O}$, which is the fluidization gas. Carbon gasification and the reaction of gases with the oxygen carrier take place in the emulsion phase. The product gases $\left(\mathrm{CO}\right.$ and $\mathrm{H}_{2}$ ) enter the emulsion phase and are quickly oxidized to $\mathrm{CO}_{2}$ and $\mathrm{H}_{2} \mathrm{O}$ by the oxygen carrier. At the coal feeding point, the volatile matter enters the bubble phase, increasing the concentration of $\mathrm{CH}_{4}, \mathrm{CO}$ and $\mathrm{H}_{2}$, i.e. the main components in the volatile matter. The volatile matter must diffuse from the bubbles to the emulsion phase to react with the oxygen carrier particles. Therefore, in the dense region, the slow diffusion of gases between bubble and emulsion phases means that the presence of $\mathrm{CO}_{2}$ is mainly due to the conversion of $\mathrm{CO}$ from carbon gasification rather than a reaction of volatile matter in the bubble phase.. Thus, $\mathrm{CO}_{2}$ concentration increases, whereas volatile gases decrease only slowly.

At the top of the dense region, the gas present in the emulsion and bubble phases is mixed. Thus, 
the concentration of $\mathrm{H}_{2}, \mathrm{CO}$, and $\mathrm{CH}_{4}$ in contact with the oxygen carrier is increased, raising the reaction rate of the oxygen carrier. Volatile matter, which was only very slightly converted in the dense region, is oxidized in the dilute region. As a consequence, $\mathrm{H}_{2}, \mathrm{CO}$ and $\mathrm{CH}_{4}$ concentrations decrease rapidly above the dense region. Volatile matter is mainly converted in the cluster phase. Where the transport phase prevails over the cluster phase $(\mathrm{z}>2.5 \mathrm{~m})$, the gas flow and composition barely change due to the low amount of reacting solids in contact with the gas flow. Once the processes happening in different regions in the fuel reactor had been described and the results provided by the model presented, validation of the model was addressed. The fluid dynamics of the fluidized bed could be validated by comparing the pressure profile obtained from experimental campaign with predictions by the model. The theoretical pressure profile could be calculated from the volumetric solids fraction, $f_{s}$, given in Fig. 4(a) as:

$$
\Delta P=\int_{0}^{H} f_{s} \rho_{\mathrm{s}} \mathrm{gd} z
$$

Fig. 5 shows both the pressure profile predicted by the model and the gauge pressure measured at different positions in the $100 \mathrm{~kW}_{\text {th }}$ CLC unit for experiment VII-5. Thus, the solids distribution predicted by the model gives a reasonably accurate description of the behaviour of the high velocity fluidized bed.

The model also predicts the flow and concentration of various gaseous compounds at the fuel reactor outlet. Thus, dry concentration of $\mathrm{CO}_{2}, \mathrm{CO}, \mathrm{H}_{2}$ and $\mathrm{CH}_{4}$ can be compared to that measured during the experimental campaign, see Fig. 6. In general, experimental and model prediction values agree to a large extent. Also, the tendency of the gas concentration values is adequately predicted. The fWGSR modifies the $\mathrm{CO} / \mathrm{H}_{2}$ ratio; nevertheless, the gas composition is far below the equilibrium condition, in which the concentration of $\mathrm{H}_{2}$ would be three times that of $\mathrm{CO}$. 
As stated above, the oxide oxygen fraction ( $\left.\eta_{\mathrm{oo}}\right)$ and the oxygen demand in the fuel reactor $\left(\Omega_{\mathrm{OD}}\right)$ were the parameters used to analyse the performance of the CLC process in the $100 \mathrm{~kW}_{\text {th }}$ unit, see Table 5. The oxide oxygen fraction was used as a target parameter by the model; thus the experimental value of $\eta_{\text {oo }}$ was replicated in the model by fitting the carbon stripper efficiency, which is not known a priori. Once the oxide oxygen fraction was fitted, the remaining parameters could be calculated. Fig. 7 shows that good agreement was found between the oxygen demand obtained during the experimental campaign and values predicted by the model. Oxygen demand decreased during experiments VII-1 to VII-4 due to a higher amount of solids present in the fuel reactor. In the rest of the experiments, the oxygen demand barely changed when temperature, solids circulation flow rate or/and steam flow into the fuel reactor was varied. In some cases, it seemed that there was a trade-off among several effects. For example, in experiments VII-5 to VII-7 the temperature was increased but the solids inventory, which is related to $\Delta \mathrm{P}$, decreased. Both variations are compensated, because an increase in temperature gives a decrease in the oxygen demand in the fuel reactor, whereas the opposite happens when the solids inventory decreases.

The model predicted the oxide oxygen fraction by fitting the efficiency of the carbon separation system, i.e. the carbon stripper. Thus, for a complete validation of the model, inputs regarding the carbon flows to and from the carbon stripper are required. Fig. 8 shows the $\eta_{\mathrm{CS}}$ values for different experimental conditions used in the selected tests, which varied between 99.1 and 99.7\%. An average value of $\eta_{\mathrm{CS}}=99.4 \%$ was calculated. This means that the design concept of the carbon stripper implemented in the $100 \mathrm{~kW}_{\text {th }}$ unit is highly effective, allowing separation of most of the char exiting the fuel reactor. The high performance of the carbon stripper was the main reason for the high $\mathrm{CO}_{2}$ capture values in the $100 \mathrm{~kW}_{\text {th }}$ unit. 
Also, the efficiency of the cyclone CY2 recovering char particles was evaluated. The values

obtained by the model are shown in Fig. 8, with an average value of $\eta_{\text {cyclone }}=97.4 \%$. Although the efficiency of the cyclone is not very low, the high flow of carbon in char leaving the fuel reactor compared to the carbon in the coal input means that the solid fuel conversion averaged $63 \%$. Although this value is uncertain, as the carbon mass balance has not been confirmed by solids measurements, it clearly indicates that a significant flow of carbon escaped from the system because char particles were not completely recovered by the cyclone CY2.

\section{Discussion}

From the results obtained in the experiments, it was concluded that the high values of $\mathrm{CO}_{2}$ capture, almost 100\%, can be reached in the $i$ G-CLC process. However, two aspects could be improved. The first one is to increase the solid fuel conversion, $\eta_{\mathrm{sf}}$, as high as possible. The second one is to minimise the oxygen demand in the exhaust gases. These issues are discussed in sections 4.1-4.3 below.

\subsection{Behaviour of the CLC unit with high solid fuel conversion}

An increase in the solid fuel conversion can be reached by increasing the efficiency of the CY2 cyclone, or by using two cyclones in series. Thus, unconverted char will be recycled and given more time to convert. Furthermore, if it is assumed that a full-scale riser is ten times higher, this will give a correspondingly increased residence time of a fine char particle for each cycle. Thus, a combination of efficient particle separation and higher riser is expected to reduce losses of unconverted char very significantly. Ideally, the solid fuel conversion should be $100 \%$. This means that no solid carbon escapes with the gaseous stream leaving the fuel reactor. This situation, i.e. $\eta_{\mathrm{SF}}=100 \%$, can be easily simulated with the mathematical model by setting the 
efficiency of the CY2 cyclone to $100 \%$.

The oxide oxygen fraction, $\eta_{\mathrm{OO}}$, and the oxygen demand in the fuel reactor, $\Omega_{\mathrm{OD}}$, are valuable parameters in evaluating the CLC process from experimental data collected during tests in the $100 \mathrm{~kW}_{\text {th }}$ unit. Nevertheless, two additional parameters more accurately reflect the meaning of oxygen demand and $\mathrm{CO}_{2}$ capture in the CLC system, which can be easily calculated from model results. These parameters were used in the previous formulation of the model (Abad et al., 2013; García-Labiano et al., 2013), and are:

a) Total oxygen demand of the flue gases, $\Omega_{\mathrm{T}}$ : this is the fraction of oxygen required to fully oxidize the unconverted gases exiting the fuel reactor to $\mathrm{CO}_{2}$ and $\mathrm{H}_{2} \mathrm{O}$ with respect the total oxygen demand of the fuel, i.e. the stoichiometric amount of oxygen required in an oxy-fuel process.

$\Omega_{T}=M_{O} \frac{\left(F_{H_{2}}+F_{C O}+4 F_{C H_{4}}\right)_{F R, o u t}}{\Omega_{\text {coul }} \dot{m}_{\text {coal }}}$

with $\Omega_{\text {coal }}$ being the oxygen demand of the coal ( $\mathrm{kg}$ oxygen per $\mathrm{kg}$ coal). When the non-solid carbon exits from the iG-CLC system, i.e. $\eta_{\mathrm{SF}}=100 \%, \Omega_{\mathrm{T}}$ states the fraction of oxygen in an oxygen polishing step downstream from the fuel reactor in comparison with the total oxygen required to burn the coal input. When char is lost from the cyclone, as in this case, the oxygen demand corresponding to unconverted carbon in char is not taken into account in $\Omega_{\mathrm{T}}$, and thus lower values than $\Omega_{\mathrm{OD}}$ are expected. However, $\Omega_{\mathrm{T}}$ gives a rapid overview of how many unburnt products exit compared to the coal input, and it also gives a useful comparison with the desired case of minimum carbon loss.

b) $\mathrm{CO}_{2}$ capture efficiency: $\eta_{\mathrm{CC}}$ includes the physical removal of $\mathrm{CO}_{2}$ that would otherwise be emitted into the atmosphere. Here, it is defined as the fraction of the carbon converted to gas in 
the CLC system and exits from the fuel reactor.

$$
\eta_{C C}=M_{C} \frac{\left(F_{C O_{2}}+F_{C O}+F_{C H_{4}}\right)_{F R, \text { out }}}{\eta_{S F} f_{C} \dot{m}_{\text {coal }}}=1-M_{C} \frac{F_{C, A R}}{\eta_{S F} f_{C} \dot{m}_{\text {coal }}}
$$

Note that in this technology, the carbon in char passing to the air reactor is burnt to $\mathrm{CO}_{2}$ with air, and therefore not captured.

Fig. 9 shows the $\mathrm{CO}_{2}$ capture efficiency predicted by the model for the experimental conditions in tests VII and VIII. As expected from the values of $\eta_{\text {oo, }}$ very high values of $\eta_{C C}$ were obtained. The average value was $\eta_{C C}=96.5 \%$. This fact indicates that the slow gasification step, which limits the conversion of char in the fuel reactor, is compensated by the highly efficient carbon stripper. The total oxygen demand from the flue gases is also shown in Fig. 9. A similar tendency to $\Omega_{\mathrm{OD}}$ was observed, but $\Omega_{\mathrm{T}}$ showed lower values than $\Omega_{\mathrm{OD}}$. The average value for the total oxygen demand was $11.4 \%$.

To evaluate the effect of the increase in the solid fuel conversion, a simulation using $\eta_{\mathrm{SF}}=100 \%$ and $\eta_{C S}=99.4 \%$, that is, the average value calculated by the model, was performed. The solids inventory corresponded to $440 \mathrm{~kg} / \mathrm{MW}_{\text {th. }}$. Predicted values for $\eta_{\mathrm{CC}}$ and $\Omega_{\mathrm{T}}$ are shown in Fig. 9. The increase in the solid fuel conversion had a heavy impact on the fuel reactor performance. When the solid fuel conversion is forced by the model to $100 \%$, the carbon fraction in the solids of the fuel reactor will increase. For example, the carbon fraction predicted by the model for test VII-5 was 1.8 wt. $\%$ for $\eta_{\mathrm{SF}}=63.8 \%$; but the carbon concentration rose to 4.1 wt. $\%$ when $\eta_{\mathrm{SF}}$ is assumed to be $100 \%$. A higher amount of char in the fuel reactor gives a higher amount of gasification products. The char conversion in the fuel reactor increases from $48.0 \%$ to $89.6 \%$. Nevertheless, a higher flow of char is passing to the carbon stripper. As the carbon stripper efficiency is maintained constant, the flow of char bypassed to the air reactor also increases. As a 
consequence, the predicted $\mathrm{CO}_{2}$ capture decreases from $96.7 \%$ to $92.4 \%$. Also a higher flow of gasification products means that the combustion of these gases in the fuel reactor should be lower. Thus, the total oxygen demand of the $i \mathrm{G}$-CLC process, $\Omega_{\mathrm{T}}$, increases from $10.7 \%$ to $18.7 \%$. This means that the oxygen required in a downstream oxygen polishing step is $18.7 \%$ of the stoichiometric oxygen required to burn the coal completely. The increase in the oxygen demand is related to a higher amount of gasification products in the fuel reactor, which are accumulated in the dilute region. Therefore, in the dilute region, the generation rate of gasification products is higher than the consumption rate of gasification products through a reaction with the oxygen carrier. This finding is contrary to the results obtained in a CLC unit consisting of a bubbling fluidized bed (Cuadrat et al., 2011b), where the only unburnt compounds came from volatile matter and gasification products were completely converted to $\mathrm{CO}_{2}$ and $\mathrm{H}_{2} \mathrm{O}$. In this case, $\Omega_{\mathrm{T}}$ was maintained constant as more char was gasified in the fuel reactor, whereas $\Omega_{\mathrm{OD}}$ decreased considerably.

\subsection{Sensitivity analysis}

The mathematical model, after validation, can be used to optimize the $i \mathrm{G}-\mathrm{CLC}$ process. Thus, operational conditions can be chosen to minimise the oxygen demand as much as possible, while seeking to maintain the $\mathrm{CO}_{2}$ capture efficiency at a high value. Experimental results in the 100 $\mathrm{kW}_{\text {th }}$ CLC unit clearly indicate a strong effect of the fuel reactor solids inventory. Also, high temperature has been shown to have benefits on oxygen demand. However, no effect of the global circulation was seen (Markström et al., 2013a). There is no clear explanation for this, but it may be related to poor contact of gases with the oxygen carrier or a low variation in the solids conversion due to the circulation rate being sufficiently high. These effects had been predicted in 
previous papers (Abad et al., 2013; García-Labiano et al., 2013). For example, unconverted gases were identified as volatile matter with low contact efficiency with solid particles and accumulation of gasification products in the dilute region. Also, the predicted effect of the circulation of solids on the oxygen demand is not significant for variations in the solids conversion lower than 0.6 (García-Labiano et al., 2013), i.e. for cases where the average reactivity of particles is barely affected (Abad et al., 2007).

A sensitivity analysis was performed on these operational conditions to evaluate the parameters which have a major influence on the oxygen demand and $\mathrm{CO}_{2}$ capture. The operational conditions corresponding to test VII-5, assuming that there are no losses of char through the cyclone, i.e. $\eta_{\mathrm{SF}}=100 \%$, were selected as a reference. In this case, a standard method for the sensitivity analysis, such as those used in a previous paper (García-Labiano et al., 2013), was not used. Fuel reactor temperature, pressure drop, solids circulation flow rate or steam flow to the fuel reactor were varied individually in a range of realistic values to evaluate the expected variation in oxygen demand or $\mathrm{CO}_{2}$ capture. The steam flow was changed between 2 and 18 $\mathrm{Nm}^{3} / \mathrm{h}$. Temperature was varied between 900 and $1000^{\circ} \mathrm{C}$. The pressure drop varied between 10 and $30 \mathrm{kPa}$. These values corresponded to a solids inventory in the fuel reactor of between 220 and $660 \mathrm{~kg} / \mathrm{MW}_{\text {th }}$. Furthermore, the solids circulation rate was varied between 1000 and 5000 $\mathrm{kg} / \mathrm{h}$, corresponding to an oxygen carrier to fuel ratio, $\phi$, between 1.5 and 7.5. The oxygen carrier to fuel ratio was calculated with the following equation (García-Labiano et al., 2013):

$$
\phi=\frac{R_{O C} \dot{m}_{O C}}{\Omega_{\text {coal }} \dot{m}_{\text {coal }}}
$$

Predicted results are shown in Fig. 10. Little effect on the oxygen demand and $\mathrm{CO}_{2}$ capture was observed from a variation of the steam flow. A slight increase in the $\mathrm{CO}_{2}$ capture is related to a higher availability of steam for char gasification. Nevertheless, steam is continuously 
regenerated by oxidation of $\mathrm{H}_{2}$ with the oxygen carrier. Thus, the initial amount of steam has minor relevance to oxygen demand, but this steam needs to be generated by water evaporation requiring energy consumption and imposing an energy penalty on the global process. Taking into account the limited effect of an increase insteam flow on the performance of the process, the steam flow to the fuel reactor should be as low as the fuel reactor design allows.

More relevant are the effects of temperature, pressure drop and solids circulation rate. For all these operational conditions, a beneficial effect on the oxygen demand is found because:

a) an increase in the temperature increases the oxygen carrier reaction rate with gaseous reactants;

b) an increase in the pressure drop-corresponding to an increase in the solids inventory- means more oxygen carrier to oxidize the reducing gases; and

c) an increase in the solids circulation rate increases the average reactivity of the oxygen carrier.

Fig. 10 shows that the oxygen demand can be decreased by increasing temperature or solids circulation flow rate. However, a lower effect is shown for high values of solids flow, corresponding to low values of solids conversion variation. Also an increase in the solids circulation flow rate promotes a decrease in the $\mathrm{CO}_{2}$ capture efficiency. Thus, the possibility of using high values of solids circulation rate is limited to an oxygen carrier to fuel ratio $\phi=5$ to avoid a drop in the $\mathrm{CO}_{2}$ capture below 90\%. Lower $\phi$ values would be required if the efficiency of the carbon stripper was lower (García-Labiano et al., 2013).

An increase in the pressure drop or the temperature gives a beneficial effect on the $\mathrm{CO}_{2}$ capture and oxygen demand. Thus, it would be desirable to operate at the highest temperature possible and with high solids inventory. The maximum pressure drop simulated was $30 \mathrm{kPa}$, corresponding to a solids inventory of $660 \mathrm{~kg} / \mathrm{MW}_{\mathrm{th}}$. A higher pressure drop could be difficult to 
reach under steady-state conditions.

The solids inventory per $\mathrm{MW}_{\text {th }}$ can be increased by decreasing the coal load, but maintaining the pressure drop constant. Fig. 11 shows the $\mathrm{CO}_{2}$ capture and oxygen demand predicted for test VII-5 when the coal flow is decreased from 12.6 to $3 \mathrm{~kg} / \mathrm{h}$. The corresponding solids inventory, in $\mathrm{kg}$ per $\mathrm{MW}_{\mathrm{th}}$, is also shown in the $\mathrm{x}$-axis. The oxygen demand is decreased below $10 \%$ whereas $\mathrm{CO}_{2}$ capture is almost $95 \%$ for the lowest coal feeding rate. Nevertheless, a high amount of solids in the fuel reactor is not desirable because of the incremental in the fuel reactor section per thermal MW and operational costs.

\subsection{Optimization of the $i \mathrm{G}$-CLC process}

Taking into account all of the above, the optimal operational conditions can be defined. Temperature and pressure drop are fixed at $1000^{\circ} \mathrm{C}$ and $25 \mathrm{kPa}$, respectively, as sufficiently high and achievable values. The oxygen carrier to fuel ratio was set at $\phi=5$. The solids inventory was determined at $1500 \mathrm{~kg} / \mathrm{MW}_{\text {th }}$ by setting the coal flow to $4.6 \mathrm{~kg} / \mathrm{h}$, i.e. $31.5 \mathrm{~kW}$ th. A low steam flow of $2.8 \mathrm{Nm}^{3} / \mathrm{h}$ was chosen to reduce energy penalties for steam production. This value corresponded to a steam to fixed carbon molar ratio of 1.5. Predictions by the model showed that the $\mathrm{CO}_{2}$ capture efficiency could be as high as $98.5 \%$, whereas the total oxygen demand was reduced to $9.6 \%$.

To propose improvements for a further decrease of the oxygen demand it is of help to know the origin of unburnt compounds. For this, a new simulation with the model was performed assuming that there was no gasification in the dilute region, but maintaining the fraction of char and gasification rate in the dense bed constant. In this case, the oxygen demand was as low as $3.9 \%$. Unconverted methane and gasification products in the dense region were the only origin of unburnt compounds. This fact shows the high relevance of gasification products generated in the 
dilute region on the total amount of $\mathrm{H}_{2}$ and $\mathrm{CO}$ present at the fuel reactor outlet, which represents about a $60 \%$ of the total oxygen demand.

If the oxygen demand of exhaust gases is to be further reduced, further action should be taken. These actions can include the following:

1. To use a more reactive oxygen carrier, so that reducing gases could be heavily oxidized (Mendiara et al., 2013b; García-Labiano et al., 2013; Linderholm et al., 2012).

2. To include a second fuel reactor fed by the exhaust gases, for oxidation of unburnt compounds. This concept was adopted in a $25 \mathrm{~kW}$ unit at Hamburg University of Technology (Thon et al., 2012).

3. To insert internals in the dilute region of the fuel reactor. This solution has been proposed in the literature to increase the amount of solids in the dilute region, and thus make the gas-solid contact in this zone more effective (Schmid et al., 2012).

4. To recycle exhaust gas to the fuel reactor and/or carbon stripper. In this case, a part of the flow prior to oxygen polishing is diverted and recycled to the fuel reactor or the carbon stripper. 5. To separate unburnt compounds during the liquefaction of $\mathrm{CO}_{2}$ and send these to the air reactor or the fuel reactor. The first solution has the obvious disadvantage of reducing the $\mathrm{CO}_{2}$ capture (Kempkes and Kather, 2012). In the second case, a purge stream going to the air reactor is needed to avoid accumulation of nitrogen in the gas stream, and also the $\mathrm{CO}_{2}$ capture may be decreased.

From the analysis of the fuel reactor shown in this work, the most promising options could be those that involve the combustion of gases in a place where there is no gasification, or where it was rather insignificant Thus, the use of a secondary fuel reactor or recycling gases to the carbon stripper could be considered a priori good options.

Finally, unconverted gases can be oxidised in an oxygen polishing step after the fuel reactor exit. 
However, this step could not be used in combination with option 5. Moreover, the optimization of the $i \mathrm{G}$-CLC system should consider the flow of steam fed into the fuel reactor, which should be minimised. All these issues will be addressed in future papers.

\section{Conclusions}

A model to predict the behaviour of the fuel reactor in a Chemical Looping Combustion (CLC) process with coal was validated against results obtained in a $100 \mathrm{~kW}_{\text {th }}$ CLC unit erected at Chalmers University of Technology. The model covered the processes affecting the reaction of fuel with the oxygen carrier, such as reactor fluid dynamics, reactivity of the oxygen carrier and the gasification reactivity; also the effect of a carbon separation system, i.e. the carbon stripper, on the fuel reactor performance is evaluated.

Good agreement was found between theoretical and experimental values, and the general tendency of gas concentrations was adequately predicted. The oxygen demand in the fuel reactor $\left(\Omega_{\mathrm{OD}}\right)$ due to unconverted gases was also properly predicted in all cases. The model showed that high values in $\Omega_{\mathrm{OD}}$ obtained during experiments were mainly due to the low solids inventory used in the plant. The main unburnt compounds were gasification products accumulated in the dilute region. Also methane was not fully converted because of the low reactivity of this gas with ilmenite particles. These facts prevented complete combustion of gaseous products in the fuel reactor. The high values of the $\mathrm{CO}_{2}$ capture efficiency obtained, about $\eta_{\mathrm{CC}}=97 \%$, were due to the highly efficient carbon stripper. The average carbon stripper efficiency was $99.4 \%$. Model simulations showed that the reactor temperature, the solids circulation flow rate and the solids inventory were the most significant operating conditions affecting the oxygen demand. However, high values of the solids circulation flow rate must be prevented because of the 
decrease in $\mathrm{CO}_{2}$ capture. Finally, the capability of the CLC process with coal to capture $\mathrm{CO}_{2}$ was evaluated. A $\mathrm{CO}_{2}$ capture efficiency of $\eta_{\mathrm{CC}}=98.5 \%$ and a total oxygen demand of $\Omega_{\mathrm{T}}=$ $9.6 \%$ was predicted, operating at $1000^{\circ} \mathrm{C}$ and $1500 \mathrm{~kg} / \mathrm{MW}_{\text {th }}$ in the fuel reactor.

\section{Acknowledgements}

This work was partially supported by the European Commission, under the RFCS program (ECLAIR Project, Contract RFC-PP-07011), Alstom Power Boilers, and the Spanish Ministry for Science and Innovation via the ENE2010-19550 project.

\section{References}

Abad, A., Adánez, J., García-Labiano, F., de Diego, L.F., Gayán, P., Celaya, J., 2007. Mapping of the range of operational conditions for $\mathrm{Cu}-, \mathrm{Fe}-$, and Ni-based oxygen carriers in chemical-looping combustion. Chem. Eng. Sci. 62, 533-549.

Abad, A., Adánez, J., Cuadrat, A., García-Labiano, F., Gayán P., de Diego, L.F., 2011. Kinetics of redox reactions of ilmenite for chemical-looping combustion. Chem. Eng. Sci. 66, 689702.

Abad, A., Gayán, P., de Diego, L.F., García-Labiano, F., Adánez, J., 2013. Fuel reactor modelling in chemical-looping combustion of coal: 1.model formulation. Chem. Eng. Sci. 87, 277-293.

Adánez, J., Cuadrat, A., Abad, A., Gayán, P., de Diego, L.F., García-Labiano, F., 2010. Ilmenite Activation during Consecutive Redox Cycles in Chemical-Looping Combustion. Energy Fuels 24, 1402-1413.

Adanez, J., Abad, A., Garcia-Labiano, F., Gayan, P., L.F. de Diego, 2012. Progress in ChemicalLooping Combustion and Reforming technologies. Prog. En. Comb. Sci. 38, 215-282. 
Berguerand, N., Lyngfelt, A., 2009. Chemical-Looping Combustion of Petroleum Coke Using Ilmenite in a $10 \mathrm{kWth}$ Unit-High-Temperature Operation. Energy Fuels 23, 5257-5268.

Berguerand, N., Lyngfelt, A., Mattisson T., Markström, P., 2011. Chemical Looping Combustion of Solid Fuels in a $10 \mathrm{kWth}$ Unit. Oil \& Gas Science and Technology - Revue IFP Energies nouvelles 66, 181-191.

Brown, T.A., Dennis, J.S., Scott, S.A., Davidson, J.F., Hayhurst, A.N., 2010. Gasification and Chemical-Looping Combustion of a Lignite Char in a Fluidized Bed of Iron Oxide. Energy Fuels 24, 3034-3048.

Cao, Y., Pan, W.-P., 2006. Investigation of Chemical Looping Combustion by Solid Fuels. 1. Process Analysis. Energy Fuels 20, 1836-1844.

Cuadrat, A., Linderholm, C., Abad, A., Lyngfelt, A., Adánez, J., 2011a. Influence of Limestone Addition in a $10 \mathrm{kWth}$ Chemical-Looping Combustion Unit Operated with Petcoke. Energy Fuels 25, 4818-4828.

Cuadrat, A., Abad, A., García-Labiano, F., Gayán, P., de Diego L.F., Adánez, J., 2011b. The use of ilmenite as oxygen-carrier in a $500 \mathrm{Wth}$ Chemical-Looping Coal Combustion unit. Int. J. Greenhouse Gas Control 5, 1630-1642.

Cuadrat, A., Abad, A., García-Labiano, F., Gayán, P., de Diego L.F., Adánez, J., 2012a. Effect of operating conditions in Chemical-Looping Combustion of coal in a 500 Wth unit. Int. J. Greenhouse Gas Control 6, 153-163.

Cuadrat, A., Abad, A., García-Labiano, F., Gayán, P., de Diego L.F., Adánez, J., $2012 b$. Relevance of the coal rank on the performance of the in situ gasification chemical-looping combustion. Chem. Eng. J. 195-196, 91-102.

Cuadrat, A., Abad, A., Gayán, P., de Diego, L.F., García-Labiano F., Adánez, J., 2012c.

Theoretical approach on the CLC performance with solid fuels: Optimizing the solids 
inventory. Fuel 97, 536-551.

Cuadrat, A., Abad, A., Adánez, J., de Diego, L.F., García-Labiano, F., Gayán, P., 2012d.

Behavior of ilmenite as oxygen carrier in chemical-looping combustion. Fuel Proc. Tech. 94, 101-112.

García-Labiano, F., de Diego, L.F., Gayán, P., Abad A., Adánez, J., 2013. Fuel reactor modelling in chemical-looping combustion of coal: 2-simulation and optimization. Chem. Eng. Sci. 87, 173-182.

Gayán, P., Abad, A., de Diego, L.F., García-Labiano, F., Adánez, J., 2013. Assessment of technological solutions for improving Chemical Looping Combustion of solid fuels with $\mathrm{CO}_{2}$ capture. Chem. Eng. J. http://dx.doi.org/10.1016/j.cej.2013.08.004.

Graven, W., Long, J., 1954. Kinetics and Mechanisms of the Two Opposing Reactions of the Equilibrium $\mathrm{CO}+\mathrm{H}_{2} \mathrm{O} \leftrightarrow \mathrm{CO}_{2}+\mathrm{H}_{2}$. J. Am. Chem. Soc. 76, 2602-2608.

Gu, H., Shen, L., Xiao, J., Zhang, S., Song, T., 2011. Chemical Looping Combustion of Biomass/Coal with Natural Iron Ore as Oxygen Carrier in a Continuous Reactor. Energy Fuels 25, 446-455.

Kempkes, V., Kather, A., 2012. Chemical Looping Combustion: Comparative Analysis of two Different Overall Process Configurations for Removing Unburnt Gaseous Components. Proc. $2^{\text {nd }}$ Int. Conf. Chemical Looping, Darmstadt, Germany.

Kramp, M., Thon, A., Hatge, E.U., Heinrich S., Werther, J., 2012. Carbon Stripping - A Critical Process Step in Chemical Looping Combustion of Solid Fuels. Chem. Eng. Tech. 35, 497507.

Linderholm, C., Lyngfelt, A., Cuadrat, A., Jerndal, E., 2012. Chemical-looping combustion of solid fuels - Operation in $10 \mathrm{~kW}$ unit with two fuels, above-bed and in-bed fuel feed and two oxygen carriers, manganese ore and ilmenite. Fuel 102, 808-822. 
Mahalatkar, K., Kuhlman, J., Huckaby, E.D., O’Brien, T., 2011. CFD simulation of a chemicallooping fuel reactor utilizing solid fuel. Chem. Eng. Sci. 66, 3617-3627.

Markström, P., Linderholm, C., Lyngfelt, A., 2013a. Analytical model of gas conversion in a 100 $\mathrm{kW}$ chemical-looping combustor for solid fuels-Comparison with operational results. Chem. Eng. Sci 96, 131-141.

Markström, P., Linderholm, C., Lyngfelt, A., 2013b. Chemical-looping combustion of solid fuels - Design and operation of a $100 \mathrm{~kW}$ unit with bituminous coal. Int. J. of Greenhouse Gas Control 15, 150-162.

Matthesius, G.A., Morris, R.M., Desai, M.J., 1987. Prediction of the volatile matter in coal from ultimate and proximate analyses. J. S. Afr. Inst. Min. Metall. 87, 157-161.

Mendiara, T., García-Labiano, F., Gayán, P., Abad, A., de Diego, L.F., Adánez, J., 2013a. Evaluation of the use of different coals in Chemical Looping Combustion using a bauxite waste as oxygen carrier. Fuel 106, 814-826.

Mendiara, T., de Diego, L.F., García-Labiano, F., Gayán, P., Abad, A., Adánez, J., 2013b. Behaviour of a bauxite waste material as oxygen carrier in a 500 Wth CLC unit with coal. Int. J. Greenhouse Gas Control 17, 170-182.

Orth, M., Ströhle J., Epple, B., 2012. Design and Operation of a 1 MWth Chemical Looping Plant. Proc. $2^{\text {nd }}$ Int. Conf. Chemical Looping, Darmstadt, Germany.

Schmid, J.C., Pröll, T., Kitzler, H., Pfeifer, C., Hofbauer, H., 2012. Cold flow model investigations of the countercurrent flow of a dual circulating fluidized bed gasifier. Biomass Conv. Bioref. 2, 229-244.

Schöny, G., Pallarès, D., Leion, H., Wolf, J., 2011. Assessment of the Scale-Up and Operational Design of the Fuel Reactor in Chemical Looping Combustion. Proc. $36^{\text {th }}$ Int. Tech. Conf. Clean Coal \& Fuel Systems, Clearwater, Florida, USA. 
Song, T., Shen, T., Shen, L., Xiao, J., Gu, H., Zhang, S., 2013. Evaluation of hematite oxygen carrier in chemical-looping combustion of coal. Fuel 104, 244-252.

Ströhle, J., Orth, M., Epple, B., 2010. Simulation of the fuel reactor of a 1 MWth chemical looping plant for coal. Proc. ${ }^{\text {st }}$ Int. Conf. Chemical Looping, Lyon, France.

Thon, A., Kramp, M., Hartge, E.-U., Heinrich, S., Werther, J., 2012. Operational experience with a coupled fluidized bed system for chemical looping combustion of solid fuels. Proc. $2^{\text {nd }}$ Int. Conf. Chemical Looping, Darmstadt, Germany. 


\section{Figure Captions}

Fig. 1. Reactor scheme of the $i \mathrm{G}-\mathrm{CLC}$ process for solid fuel.

Fig. 2. Gas and solids distribution in the fuel reactor, considered as a high-velocity fluidized bed reactor.

Fig. 3. Schematic picture of the $100 \mathrm{~kW}_{\text {th }}$ CLC system at Chalmers UT (Markström et al., 2013b). Numbers 1-5 indicate modifications in the model compared to the model concept for the $1 \mathrm{MW}_{\text {th }}$ unit at TU Darmstadt (Abad et al., 2013).

Fig. 4. Axial profiles of (a) solids fraction and gas velocity; (b) flow of gases; and (c) molar fraction of gases ( $\mathrm{N}_{2}$ free). Model prediction for test VII-5.

Fig. 5. Pressure profile from the experiment VII-5. Continuous lines: model predictions; Symbols: experimental results.

Fig. 6. Dry concentration of $\mathrm{CO}_{2}, \mathrm{CO}, \mathrm{H}_{2}$ and $\mathrm{CH}_{4}$ at the fuel reactor exit obtained for tests VII and VIII evaluated in this work. Continuous lines: experimental results; Dashed lines: model predictions.

Fig. 7. Oxygen demand in the fuel reactor $\left(\Omega_{\mathrm{OD}}\right)$ and oxide oxygen capture efficiency $\left(\eta_{\mathrm{OO}}\right)$ obtained for tests VII and VIII evaluated in this work. Continuous lines: experimental results; Dashed lines: model predictions.

Fig. 8. Efficiency of the carbon separation system, $\eta_{\mathrm{CS}}$, and efficiency of char recovery in the cyclone, $\eta_{\text {cyclone, }}$ predicted by the model for the different experimental conditions in VII and VIII tests.

Fig. 9. $\mathrm{CO}_{2}$ capture effiency $\left(\eta_{\mathrm{CC}}\right)$ and total oxygen demand $\left(\Omega_{\mathrm{T}}\right)$ predicted by the model for the different experimental conditions in VII and VIII tests. Solid symbols: for experimental $\eta_{\mathrm{SF}}$; 
Empty symbols: for $\eta_{\mathrm{SF}}=100 \%$.

Fig. 10. Effect of operating conditions (temperature: ${ }^{\boldsymbol{\Delta}}$; pressure drop: $\bullet$; steam flow: $\bullet$; solids circulation flow: -- ) on the $\mathrm{CO}_{2}$ capture $\left(\eta_{\mathrm{CC}}\right)$ and total oxygen demand $\left(\Omega_{\mathrm{T}}\right)$. Reference test VII-5.

Fig. 11. Effect of the coal feeding rate on the predicted values for $\mathrm{CO}_{2}$ capture $\left(\eta_{\mathrm{CC}}\right)$ and oxygen demand $\left(\Omega_{\mathrm{T}}\right)$.Reference test VII-5. 


\section{Table 1}

Geometrical parameters of the fuel reactor in the $100 \mathrm{~kW}_{\text {th }}$ CLC.

Reactor geometry m

Height, $H_{r} \quad 5.0$

Diameter, $d_{\text {react }} \quad 0.154$

Height of stream from LS2, $H_{1} \quad 0.05$

Height of overflow to $\mathrm{LS} 3, \mathrm{H}_{2} \quad 1.0$

Height of inlet in $\mathrm{C}, H_{3} \quad 1.9$

Height of inlet in $\mathrm{B}, H_{4} \quad 2.1$

Height of inlet in A, $H_{5} \quad 2.3$ 


\section{Table 2}

Composition of the El Cerrejón coal (wt.\%).

\begin{tabular}{ll}
\hline Moisture & 13.8 \\
Volatile matter & 29.4 \\
Fixed carbon & 48.2 \\
Ash & 8.6 \\
\hline $\mathrm{C}$ & 65.4 \\
$\mathrm{H}$ & 4.6 \\
$\mathrm{~N}$ & 1.3 \\
$\mathrm{~S}$ & 0.6 \\
$\mathrm{O}^{\mathrm{a}}$ & 5.7 \\
\hline
\end{tabular}

${ }^{a}$ by difference 


\section{Table 3}

Distribution of products from devolatilization of El Cerrejón coal (wt.\%).

\begin{tabular}{ll}
\hline Carbon & 48.2 \\
Ash & 8.6 \\
$\mathrm{CH}_{4}$ & 7.6 \\
$\mathrm{CO}$ & 25.9 \\
$\mathrm{CO}_{2}$ & 1.4 \\
$\mathrm{H}_{2}$ & 3.6 \\
$\mathrm{H}_{2} \mathrm{O}$ & 2.4 \\
$\mathrm{~N}_{2}$ & 1.6 \\
$\mathrm{SO}_{2}$ & 0.7 \\
\hline
\end{tabular}




\section{Table 4}

Operational conditions in experiments during the seventh and eighth periods carried out in the $100 \mathrm{~kW}$ th unit (Markström et al., $2013 \mathrm{~b}$ ). $F_{g, i}$ represents the gas flow entering by point $i$ in Fig. 2 .

\begin{tabular}{lccccccccccc}
\hline Test: & VII-1 & VII-2 & VII-3 & VII-4 & VII-5 & VII-6 & VII-7 & VII-8 & VII-9 & VIII-1 & VIII-2 \\
\hline $\mathrm{T}_{\mathrm{FR}}\left({ }^{\circ} \mathrm{C}\right)$ & 956 & 957 & 957 & 957 & 959 & 969 & 976 & 969 & 963 & 967 & 963 \\
$\Delta \mathrm{P}(\mathrm{kPa})$ & 15.4 & 20.2 & 22.6 & 23.4 & 20.3 & 19.6 & 15.6 & 18.3 & 18.8 & 20.4 & 22.5 \\
$\quad(\mathrm{~kg} / \mathrm{h})$ & 12.6 & 12.6 & 12.6 & 12.6 & 12.6 & 12.6 & 12.6 & 12.6 & 12.6 & 12.6 & 12.6 \\
$\quad(\mathrm{~kg} / \mathrm{h})$ & 990 & 1566 & 2142 & 2610 & 2424 & 2376 & 3210 & 2190 & 2166 & 1758 & 2394 \\
$F_{g, F R}(\mathrm{Nm} / \mathrm{h})^{\mathrm{a}}$ & 18.7 & 18.7 & 18.7 & 18.7 & 6.2 & 6.2 & 6.2 & 6.2 & 18.7 & 6.2 & 6.2 \\
$F_{g, 1}\left(\mathrm{Nm}{ }^{3} / \mathrm{h}\right)^{\mathrm{b}}$ & 4.8 & 4.8 & 4.8 & 4.8 & 4.8 & 4.8 & 4.8 & 4.8 & 4.8 & 4.8 & 4.8 \\
$F_{g, 2}\left(\mathrm{Nm}^{3} / \mathrm{h}\right)^{\mathrm{a}}$ & 1.2 & 1.2 & 1.2 & 1.2 & 1.2 & 1.2 & 1.2 & 1.2 & 1.2 & 1.2 & 1.2 \\
$F_{g, 3}\left(\mathrm{Nm}^{3} / \mathrm{h}\right)^{\mathrm{a}}$ & 1.9 & 1.9 & 1.9 & 1.9 & 1.9 & 1.9 & 1.9 & 1.9 & 1.9 & 1.9 & 1.9 \\
$F_{g, 4}\left(\mathrm{Nm}^{3} / \mathrm{h}\right)^{\mathrm{a}}$ & 21.2 & 21.2 & 21.2 & 21.2 & 21.2 & 21.2 & 21.2 & 21.2 & 21.2 & 21.2 & 21.2 \\
$F_{g, 5}\left(\mathrm{Nm}^{3} / \mathrm{h}\right)^{\mathrm{a}}$ & 7.5 & 7.5 & 7.5 & 7.5 & 7.5 & 7.5 & 13.7 & 7.5 & 7.5 & 7.5 \\
\hline
\end{tabular}

$\bar{a} 100$ vol. $\% \mathrm{H}_{2} \mathrm{O} ;{ }^{\mathrm{b}} 25.8$ vol. $\% \mathrm{H}_{2} \mathrm{O}$. 


\section{Table 5}

Solid fuel conversion $\left(\eta_{\mathrm{SF}}\right)$, oxygen demand $\left(\Omega_{\mathrm{OD}}\right)$, and the oxide oxygen fraction $\left(\eta_{\mathrm{OO}}\right)$ obtained during experimental work in $100 \mathrm{~kW}$ th $\mathrm{unit}$ (Markström et al., 2013b).

\begin{tabular}{lccccccccccc}
\hline Test: & VII-1 & VII-2 & VII-3 & VII-4 & VII-5 & VII-6 & VII-7 & VII-8 & VII-9 & VIII-1 & VIII-2 \\
\hline$\eta_{\mathrm{SF}}(\%)$ & 52.2 & 59.4 & 60.9 & 62.3 & 63.8 & 66.7 & 66.7 & 66.7 & 64.5 & 63 & 65.2 \\
$\Omega_{\mathrm{OD}}(\%)$ & 25.4 & 22.0 & 19.8 & 17.6 & 16.3 & 15.7 & 17.8 & 17.2 & 18.3 & 18.3 & 15.4 \\
$\eta_{\mathrm{OO}}(\%)$ & 98.6 & 98.0 & 97.8 & 98.0 & 98.0 & 98.7 & 97.4 & 98.8 & 98.4 & 97.4 & 97.1 \\
\hline
\end{tabular}




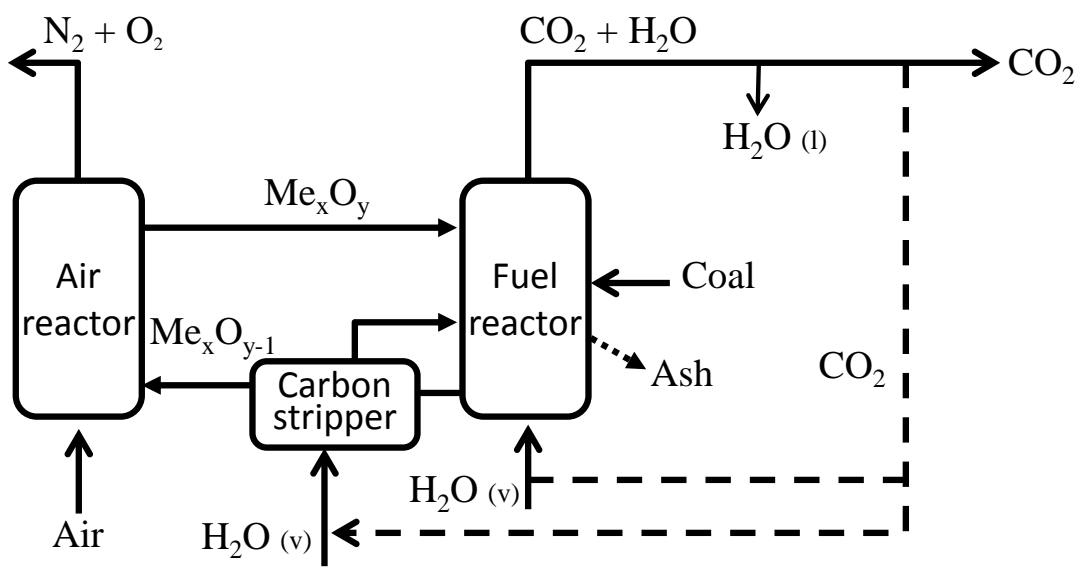

Fig. 1. Reactor scheme of the $i \mathrm{G}-\mathrm{CLC}$ process for solid fuel. 


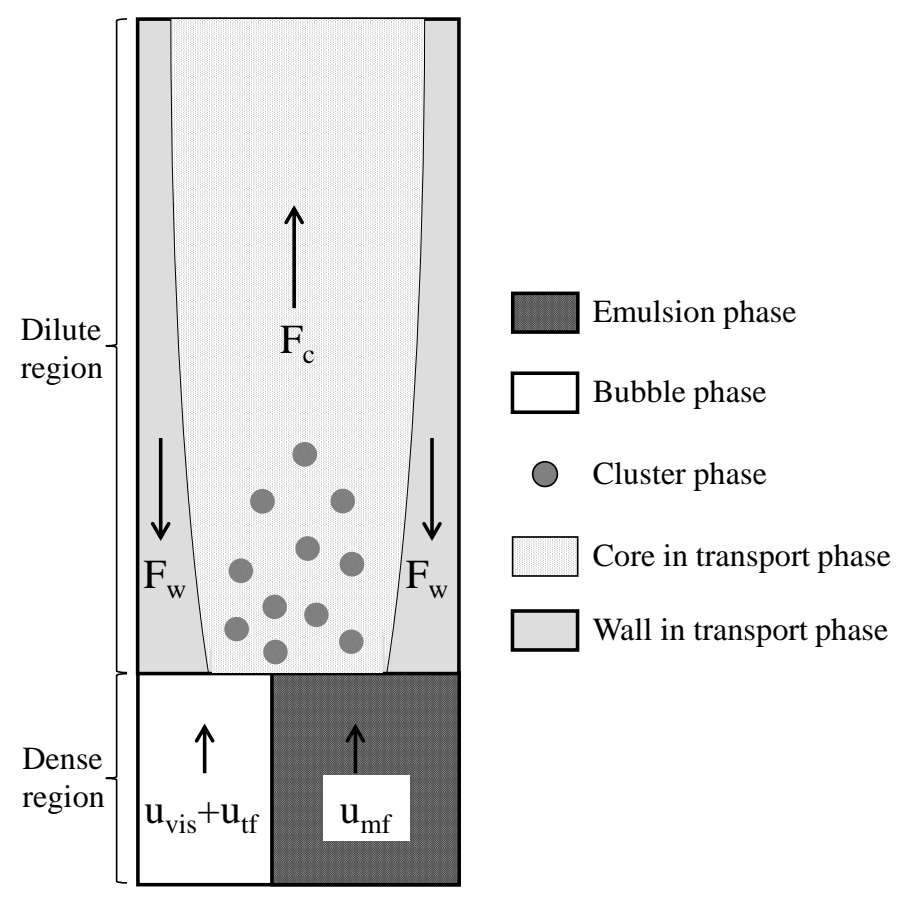

Fig. 2. Gas and solids distribution in the fuel reactor, considered as a high-velocity fluidized bed reactor. 


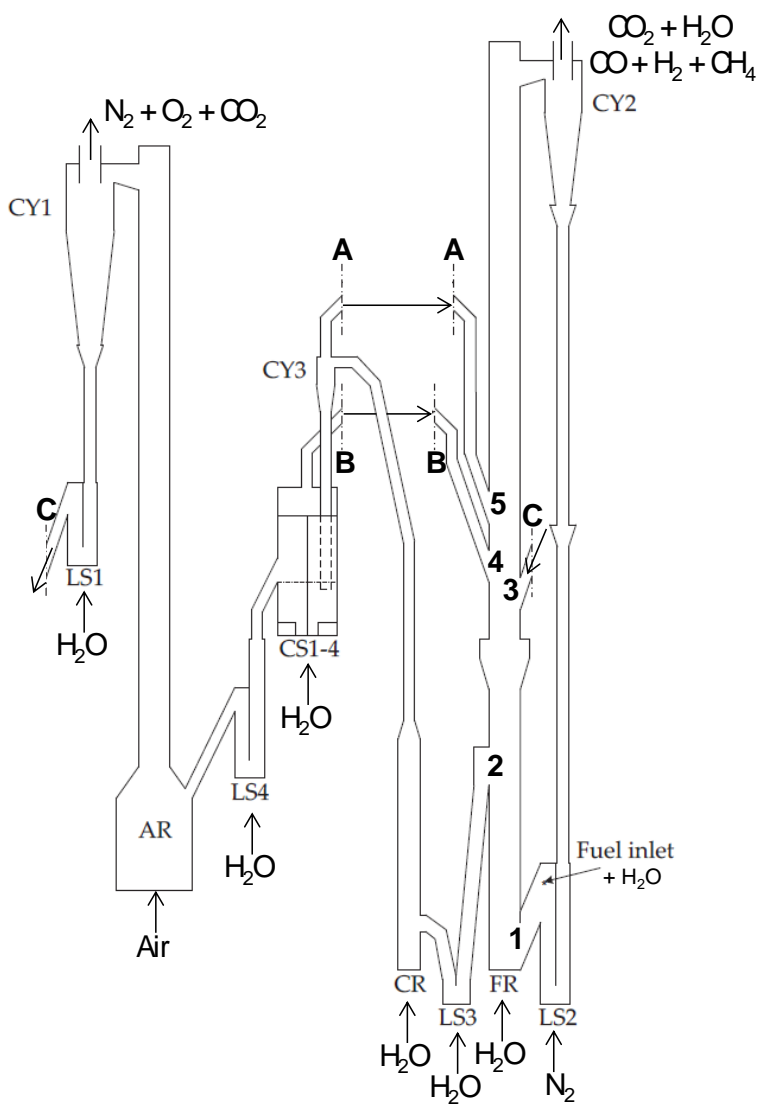

Fig. 3. Schematic picture of the $100 \mathrm{~kW}_{\text {th }}$ CLC system at Chalmers UT (Markström et al., 2013b). Numbers 1-5 indicate modifications in the model compared to the model concept for the $1 \mathrm{MW}_{\text {th }}$ unit at TU Darmstadt (Abad et al., 2013. 

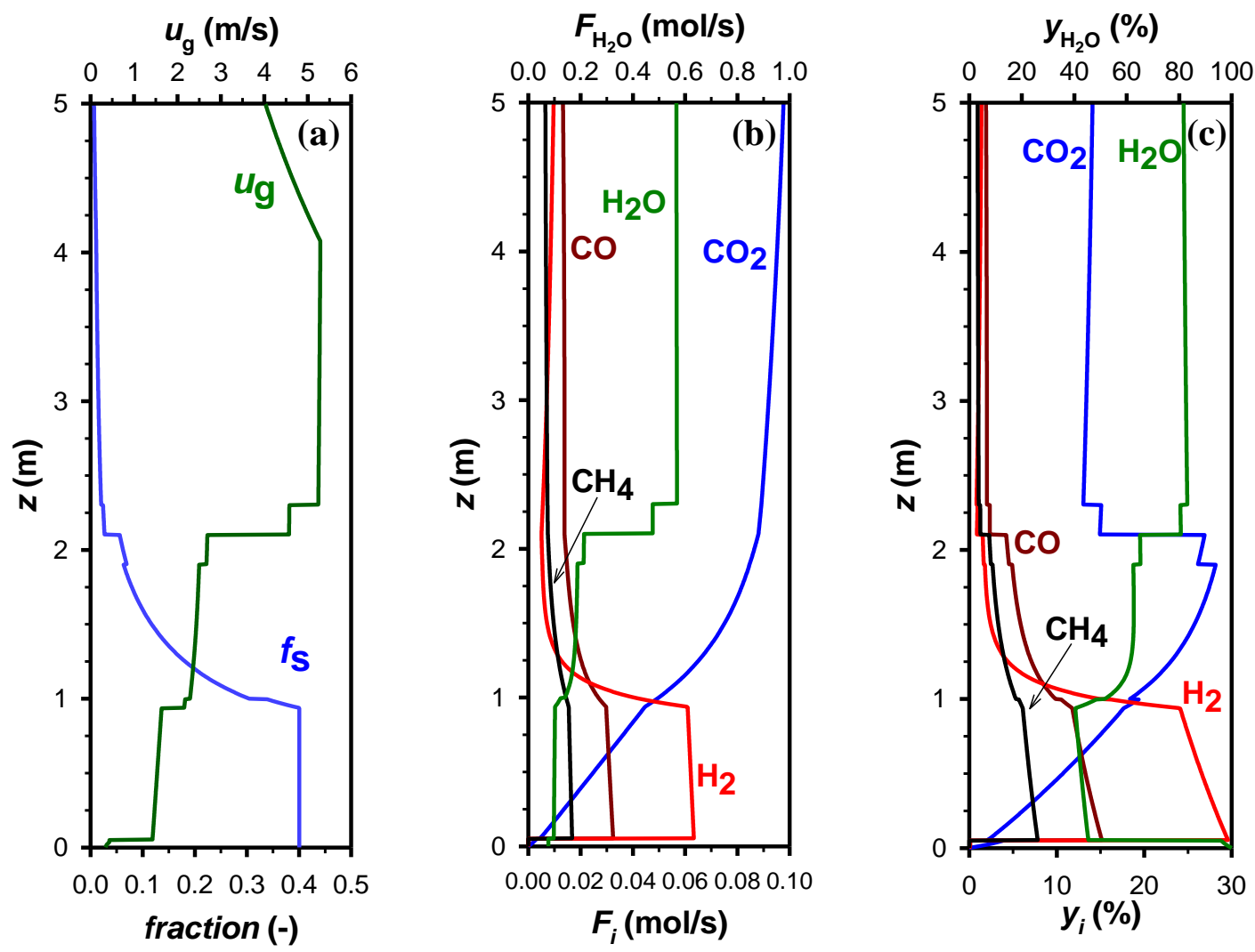

Fig. 4. Axial profiles of (a) solids fraction and gas velocity; (b) flow of gases; and (c) molar fraction of gases ( $\mathrm{N}_{2}$ free). Model prediction for test VII-5. 


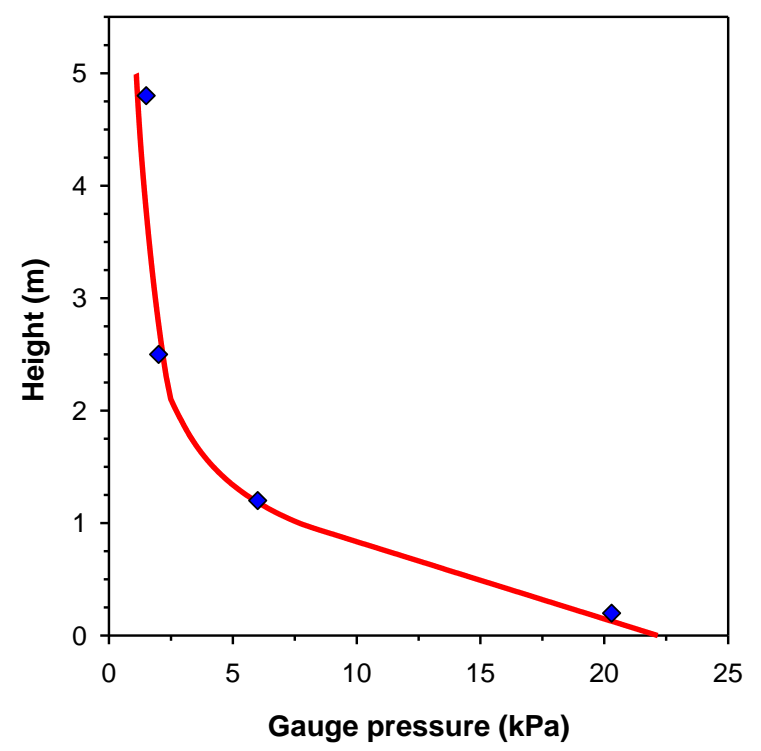

Fig. 5. Pressure profile from the experiment VII-5. Continuous lines: model predictions; Symbols: experimental results. 


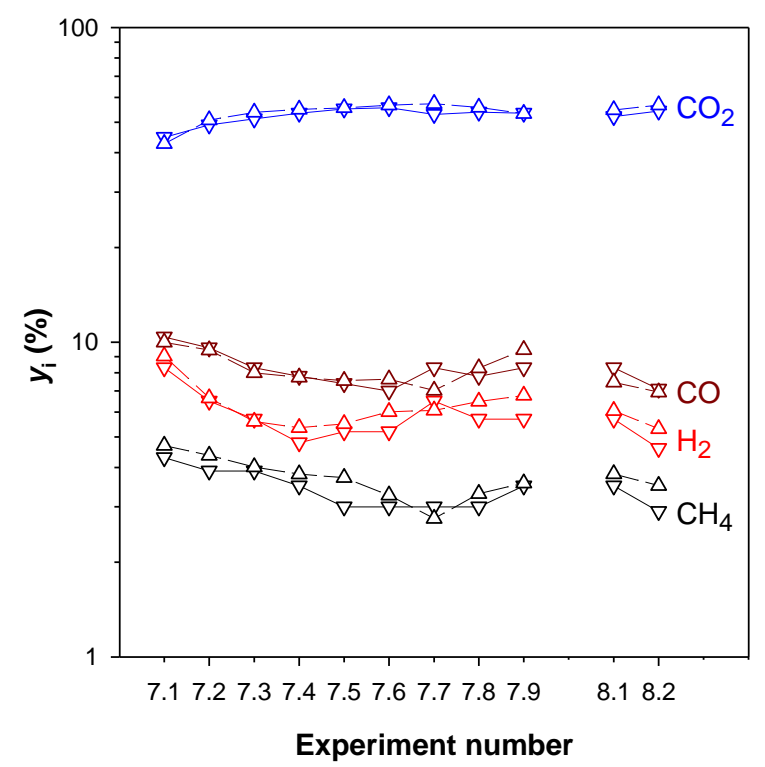

Fig. 6. Dry concentration of $\mathrm{CO}_{2}, \mathrm{CO}, \mathrm{H}_{2}$ and $\mathrm{CH}_{4}$ at the fuel reactor exit obtained for tests VII and VIII evaluated in this work. Continuous lines: experimental results; Dashed lines: model predictions. 


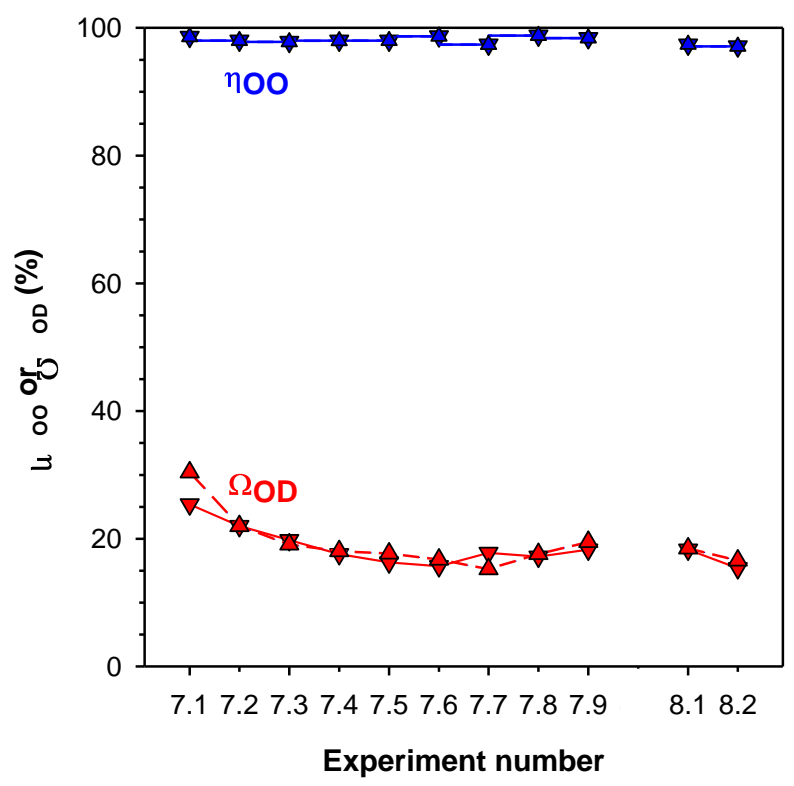

Fig. 7. Oxygen demand in the fuel reactor $\left(\Omega_{\mathrm{OD}}\right)$ and oxide oxygen capture efficiency $\left(\eta_{\mathrm{OO}}\right)$ obtained for tests VII and VIII evaluated in this work. Continuous lines: experimental results; Dashed lines: model predictions. 


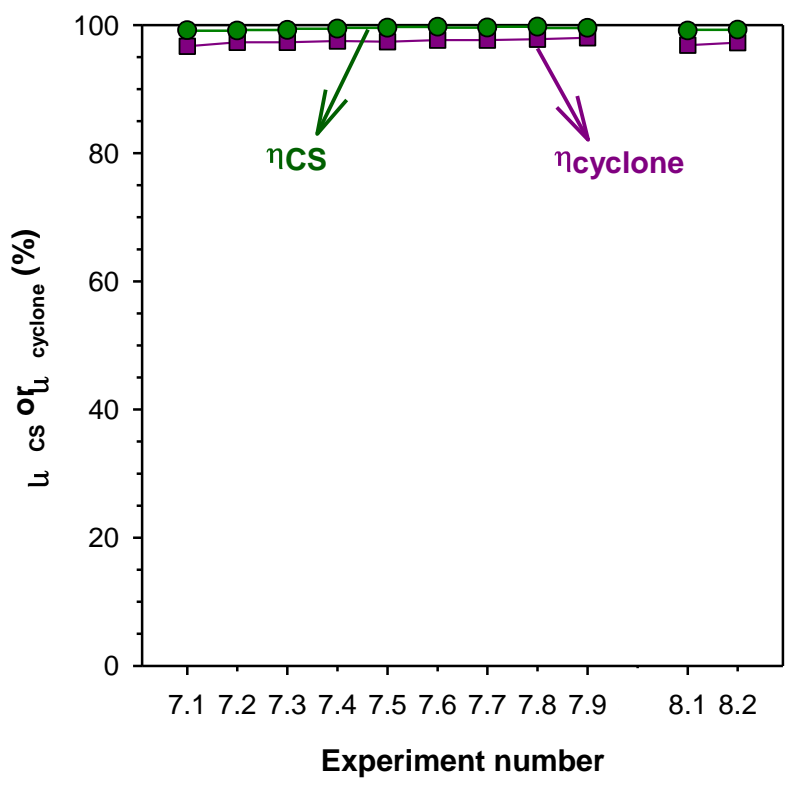

Fig. 8. Efficiency of the carbon separation system, $\eta_{C S}$, and efficiency of char recovery in the cyclone, $\eta_{\text {cyclone}}$, predicted by the model for the different experimental conditions in VII and VIII tests. 


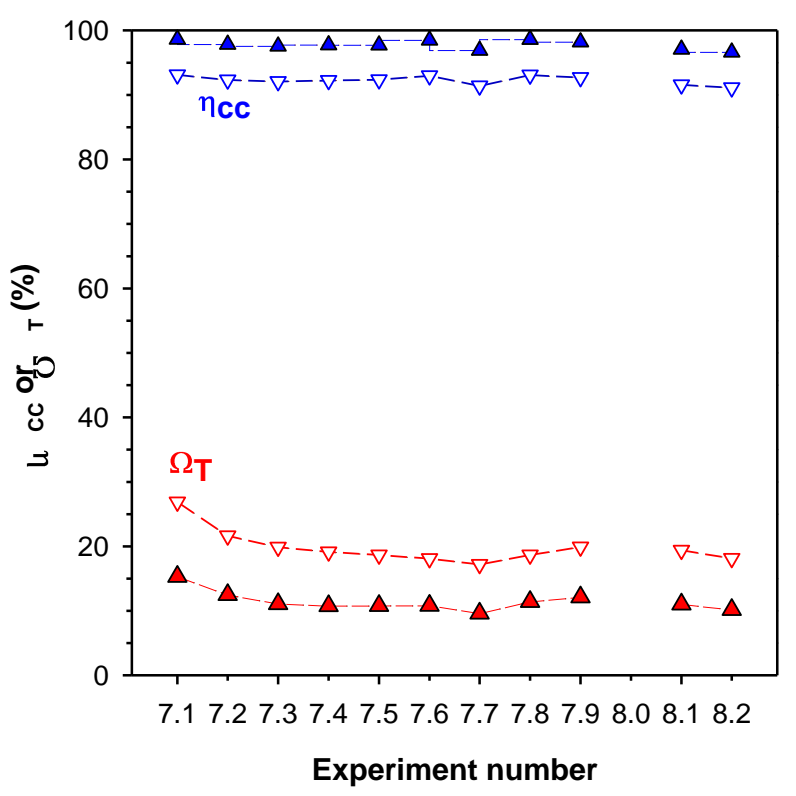

Fig. 9. $\mathrm{CO}_{2}$ capture effiency $\left(\eta_{\mathrm{CC}}\right)$ and total oxygen demand $\left(\Omega_{\mathrm{T}}\right)$ predicted by the model for the different experimental conditions in VII and VIII tests. Solid symbols: for experimental $\eta_{\mathrm{SF}}$; Empty symbols: for $\eta_{\mathrm{SF}}=100 \%$. 


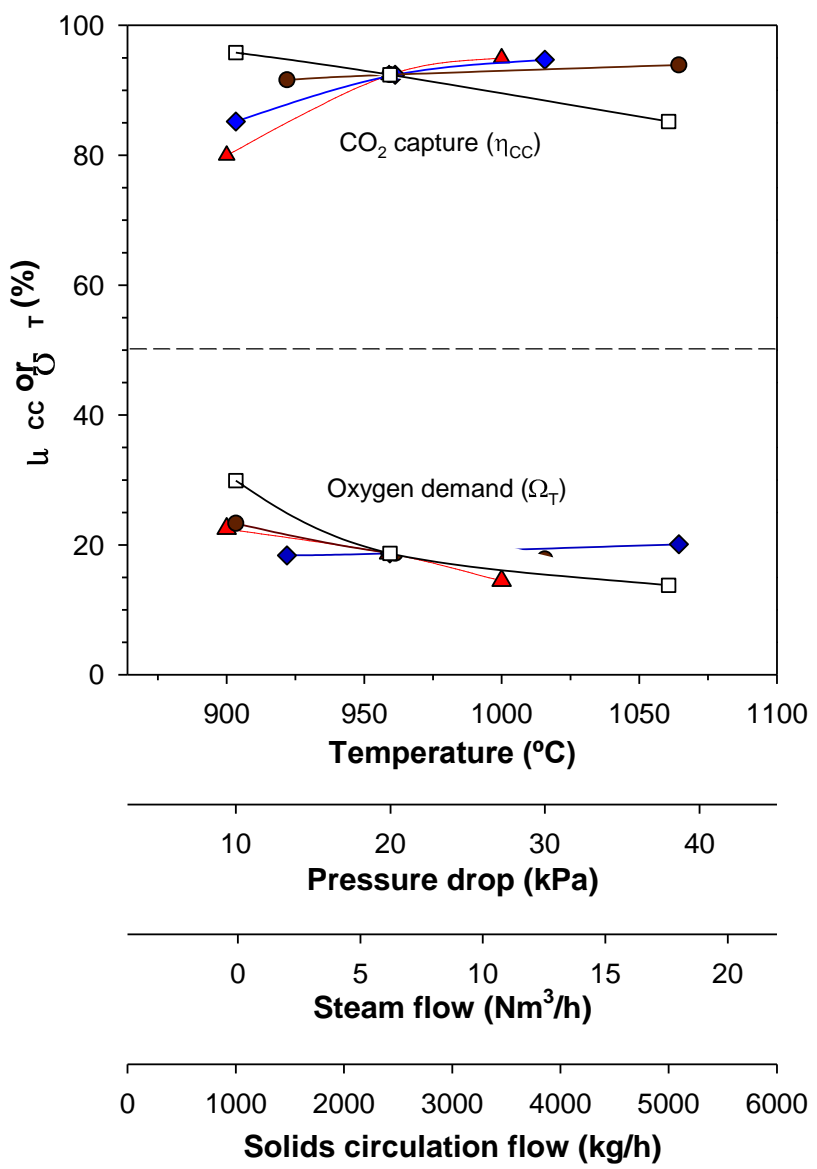

Fig. 10. Effect of operating conditions (temperature: ${ }^{\star}$; pressure drop: $\stackrel{\bullet}{-}$; steam flow: $\bullet-\bullet$; solids circulation flow: $\square$ ) on the $\mathrm{CO}_{2}$ capture $\left(\eta_{\mathrm{CC}}\right)$ and total oxygen demand $\left(\Omega_{\mathrm{T}}\right)$. Reference test VII-5. 


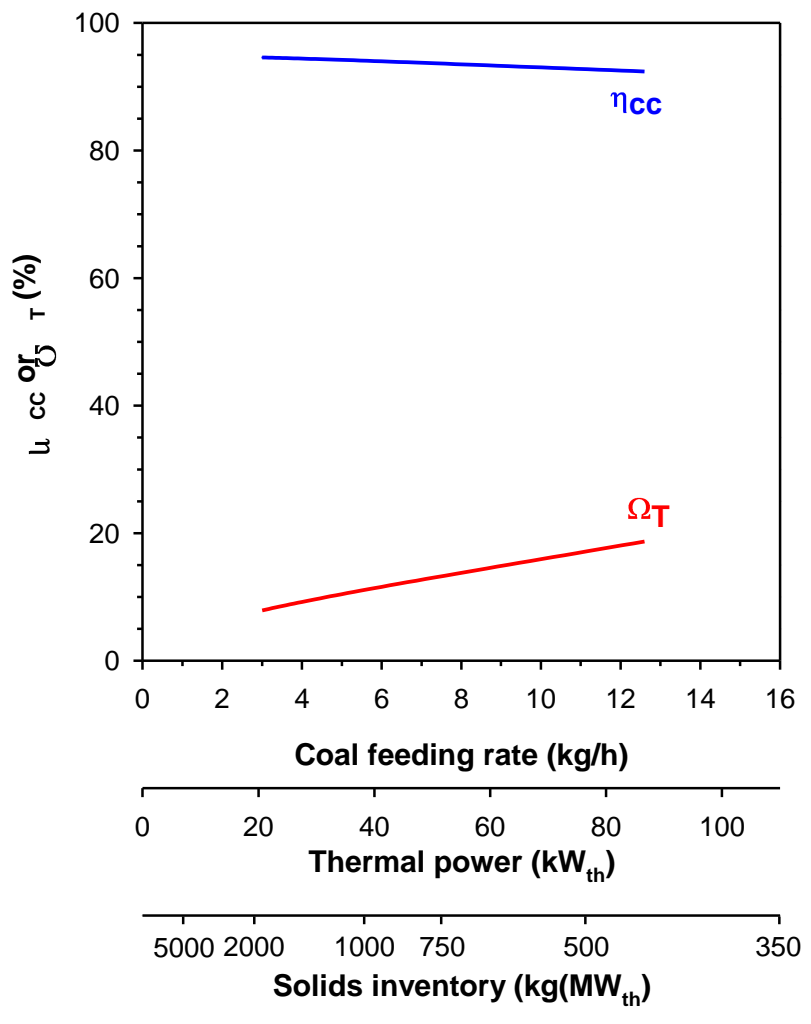

Fig. 11. Effect of the coal feeding rate on the predicted values for $\mathrm{CO}_{2}$ capture $\left(\eta_{\mathrm{CC}}\right)$ and oxygen demand $\left(\Omega_{\mathrm{T}}\right)$.Reference test VII-5. 